\title{
Src-Induced Disintegration of Adherens Junctions of Madin-Darby Canine Kidney Cells Is Dependent on Endocytosis of Cadherin and Antagonized by Tiam-1
}

\author{
Riitta Palovuori, Raija Sormunen, and Sinikka Eskelinen \\ Biocenter Oulu and the Department of Pathology, University of Oulu, University of Oulu, Finland
}

SUMMARY: The effects of Src tyrosine kinase activation in subconfluent temperature sensitive (ts)-Src-transformed MadinDarby canine kidney (MDCK) cells were analyzed by shifting them from nonpermissive $\left(40.5^{\circ} \mathrm{C}\right)$ to permissive $\left(35^{\circ} \mathrm{C}\right)$ temperature. Already, in 15 minutes, adherens junction components were released from the lateral walls and accumulated to basal surfaces. Simultaneously, membranous actin staining vanished, actin bundles appeared at the basal surface, and the cells flattened. The only component phosphorylated and translocated after the shift to $35^{\circ} \mathrm{C}$ was $\mathrm{p} 120 \mathrm{ctn}$. The epithelial-mesenchymal transition could be inhibited by a specific inhibitor of Src kinase, PP2, or by inhibiting endocytosis. Therefore, Src activation was responsible for the transition, but not because of phosphorylation of adherens junction components but by way of activation of endocytic machinery and RhoGTPase. Expression of an RacGEF, Tiam-1 (T-lymphoma invasion and metastasis gene 1), prevented flattening of Src-transformed MDCK cells at $35^{\circ} \mathrm{C}$ and resulted in accumulation of cadherin to lateral membranes. In the case where the Src-MDCK cells were cultivated at $35^{\circ} \mathrm{C}$ and shifted for short time periods to $40.5^{\circ} \mathrm{C}$, cadherin rapidly returned to lateral membranes, whereas actin and p120ctn followed hours afterward. This further supports the view that cadherin internalization is the primary target of Src kinase. We also looked at the cell morphology and distribution of cadherin and Tiam-1 in cells grown in three-dimensional gels composed of collagen and laminin or in Matrigel. At nonpermissive temperature, both Src-MDCK and Tiam-1-transfected Src-MDCK cells exhibited nonpolarized morphology in collagen I, a loose cluster in the mixture of collagen I and laminin, and a differentiated cyst in Matrigel. In growth factor-depleted Matrigel, the Src-MDCK cells grew in nondifferentiated clusters, whereas Tiam-1-transfected cells went to apoptosis. The differentiated phenotype of both cell lines could be rescued by Matrigel-conditioned medium, platelet-derived growth factor, or cholera toxin. Concomitantly, both cadherin and Tiam-1 were recruited to lateral membranes. Therefore, cadherin and Tiam-1 seem to be the key players in the differentiation process of MDCK cells. (Lab Invest 2003, 83:1901-1915).

\begin{abstract}
$P$ olarization of the epithelial cells is fundamental for the functionality of organs and tissues, and failure in their behavior leads to malignant transformation of the cells (Giancotti, 1997; Perl et al, 1998; Sastry and Horwitz, 1996; Thomas and Brugge, 1997; Wright and Huang, 1996). Src (Rous sarcoma virus gene) tyrosine kinase and small GTPases of Ras and Rho families have a central role in both differentiation and transformation processes (Frame et al, 2002; Thomas and Brugge, 1997). In epithelial cells, Src is localized both at adherens junctions (AJ) and focal adhesions and is involved in the regulation of cell adhesion (Tsukita et al, 1991). Its effect on the epithelial cell morphology has been studied either by inhibiting endogenous tyrosine phosphatases or by transfecting the cells with viral Src (v-Src) kinase (Behrens et al, 1993; Volberg et
\end{abstract}

\section{DOI: 10.1097/01.LAB.0000107009.75152.03}

Received May 8, 2003.

This work was supported by grants from the Academy of Finland and Cancer Research Foundation of Northern Finland. Dr. Riitta Palovuori is also grateful to Cancer Research Foundation of Northern Finland for a personal grant.

Address reprint requests to: Dr. Sinikka Eskelinen, University of Oulu Biocenter, Post Office Box 5000, University of Oulu, FIN-90014, Oulu, Finland.E-mail: sinikka.eskelinen@oulu.fi al, 1992). Several studies clearly show that activation of v-Src weakens cell-cell adhesion (Behrens et al, 1993; Takeda et al, 1995). However, it is difficult to definitively link this phenomenon to phosphorylation of one particular protein, and the consequences of the phosphorylation of junctional proteins by Src kinases are still controversial.

Another factor regulating the formation of AJs and tight junctions (TJs) are small GTPases of the Rho family (Fukata et al, 1999; Kaibuchi et al, 1999). The number of actin filaments, amount of E-cadherin, and $\beta$-catenin has been observed to be increased at the cell-cell adhesion sites in Madin-Darby canine kidney (MDCK) cells transformed with an active form of Rac (Ras-related C3 botulinum toxin substrate) (Takaishi et al, 1997). There are several effectors involved in the regulation of cell-cell adhesion by small GTPases: for example, IQGAP-1 (protein with IQ domains and similarity to GTPase activating proteins), which interacts with Cdc42 and Rac-1 and colocalizes with cadherin, catenin complex at the sites of cell-cell contact (Fukata et al, 1999), and $\mathrm{p} 120^{\mathrm{ctn}}$, which binds to the cytoplasmic domain of E-cadherin and has an inhibitory effect on the RhoA activity both in vitro and in vivo (Anastasiadis et al, 2000; Anastasiadis and Reynolds, 2000). The third component regulating the activity of small GTPases in epithelial cells is an RacGEF, Tiam-1 
(T-lymphoma invasion and metastasis gene 1), that together with active V12Rac promotes E-cadherinmediated cell-cell adhesion in MDCK cells (Sander et al, 1998; 1999). In addition to the linkage proteins and small GTPases, the third group of proteins involved in the regulation of cell-cell adhesion are cell-signaling proteins that often are Src substrates. Recent data has shown that disintegration of AJs is mediated by endocytosis of E-cadherin. Two players, ARF6-GTPase and Hakai have been identified as the main regulators of Src-induced cadherin internalization (Fujita et al, 2002; Palacios et al, 2001, 2002).

In the present work, we have used temperature sensitive (ts)-Src MDCK and Tiam-1-transfected Src MDCK cells as models to analyze the early effects of activated Src kinase or Rac-1 on the epithelial cell morphology and distribution of junctional components. We aimed at identifying the substrates of Src and finding correlations between phosphorylation and mobility of junctional complexes. As a second goal, we tried to separate the roles of cadherin and actin in the maintenance of cell-cell contact and tried to find the target of Tiam-1 in MDCK cells.

\section{Results}

\section{Protein Distribution in MDCK Cells after Activation of Src Kinase}

The ts-Src MDCK cells transformed with a temperature-sensitive mutant of v-Src exhibit an epithelial phenotype at a nonpermissive temperature $\left(40.5^{\circ} \mathrm{C}\right)$, but acquire a more fibroblast-like morphology cultured at the permissive temperature of $35^{\circ} \mathrm{C}$ (Behrens et al, 1993; Sormunen et al, 1999). Therefore, they are an ideal tool in studies of early events induced by Src activation because the activity can be triggered simply by a shift to a permissive temperature.

We were interested in studying the mechanism of how junctional proteins are released from their original complexes and how they are phosphorylated after a shift to a permissive temperature. The fixed SrcMDCK cells were stained with antiphosphotyrosine and anti-E-cadherin, anti-p120 ctn, anti- $\alpha$, and anti- $\beta$ catenin, anti-ZO-1, and anticlaudin antibodies as well as Alexa 568 phalloidin. The protein distribution was visualized with confocal microscopy. At the nonpermissive temperature, all of the AJ proteins lined the lateral membranes, colocalizing with tyrosine phosphorylated proteins (Fig. 1 for cadherin (for others, data not shown). Within 15 minutes after Src activation at permissive temperature, cadherin clustered at the basal surface, and lateral wall staining was broader (Fig. 1F). In 60 to 120 minutes at $35^{\circ} \mathrm{C}$, all AJ proteins clustered to basal surfaces (Figs. $1 \mathrm{H}$ and 2B for cadherin; Fig. 2, F, J, and N, for others). At the basal clusters, staining of junctional components partially colocalized with antiphosphotyrosine antibody (Figs. $1 \mathrm{H}$ and 2, B, F, and N). Concomitantly, the cells were flattened and lost their epithelial morphology. At nonpermissive temperature, tight junctional components ZO-1 and claudin lined the lateral membranes, ZO-1 colocalizing occasionally with claudin always colocalizing with antiphosphotyrosine antibody (Fig. 1, I and M, for ZO-1, claudin not shown). Within 15 minutes at permissive temperature, ZO-1 was clearly separated into two pools, narrow nonphosphorylated ribbons, and broader bands colocalizing with antiphosphotyrosine antibody (Fig. 1, J and $\mathrm{N}$ ), whereas claudin remained at the lateral walls always colocalizing with antiphosphotyrosine antibody (data not shown). Thus, AJs were completely disintegrated because of Src activation, but the components of TJs kept their position in Src-activated cells. In confluent MDCK cells, actin is a component of AJ, and stress fibers are short and few in number (Vääräniemi et al, 1994, 1999). In 15 minutes at $35^{\circ} \mathrm{C}$, actin stress fibers started to accumulate to the basal surface of the cells, and staining at lateral walls was weaker (data not shown). In 120 minutes at $35^{\circ} \mathrm{C}$, large actin bundles were seen at the basal surfaces, and lateral actin had vanished (Fig. 2, Q and R). Thus, Src activation seemed to favor actin polymerization to stress fibers, a process in which activation of Rho is a necessary step.

\section{Inhibition of Src Kinase by PP2}

To analyze whether the observed alterations in SrcMDCK cells after shift to $35^{\circ} \mathrm{C}$ were caused by activation of $\mathrm{Src}$, we repeated the experiments in the presence of the specific Src inhibitor, PP2 (Brandt et al, 2002). PP2 completely inhibited the morphologic alterations of Src-MDCK cells at permissive temperature. Figure 2 shows the distribution of tyrosinephosphorylated proteins stained with antiphosphotyrosine antibodies E-cadherin, $\mathrm{p} 120^{\mathrm{ctn}}, \alpha-$ and $\beta$-catenin, and actin filaments after incubation of SrcMDCK cells without or with $50 \mu \mathrm{M}$ of PP2 for 15 minutes at $40.5^{\circ} \mathrm{C}$ and thereafter for 120 minutes at $35^{\circ} \mathrm{C}$. In the presence of inhibitor, the morphology of the cells remained cubic, antiphosphotyrosine staining at lateral membranes was narrow and discontinuous, and cadherin and $\alpha$ - and $\beta$-catenin remained at the lateral walls. Surprisingly, p120 $0^{\text {ctn }}$ was mainly located in cytoplasm, and only narrow membrane staining was observed (Fig. 2, G and H). Also, the number of stress fibers in the presence of PP2 was higher than in control cells grown at nonpermissive temperature. Still, it is obvious that Src activation seems to be responsible for the epithelial-mesenchymal transition of the MDCK cells and removal of the components of AJs from lateral membranes.

\section{Inhibition of Endocytosis by Nocodazole Treatment or by Lowering Intracellular $\mathrm{pH}$}

Recent data has shown that disintegration of AJs takes place through endocytosis of cadherin (Palacios et al, 2001, 2002). To test this in our system, we repeated the temperature shift experiments in the presence of nocodazole, a tubulin-disrupting agent that is known to inhibit endocytosis. In these circumstances, the cells kept their epithelial morphology, and actin and cadherin remained at lateral membranes 

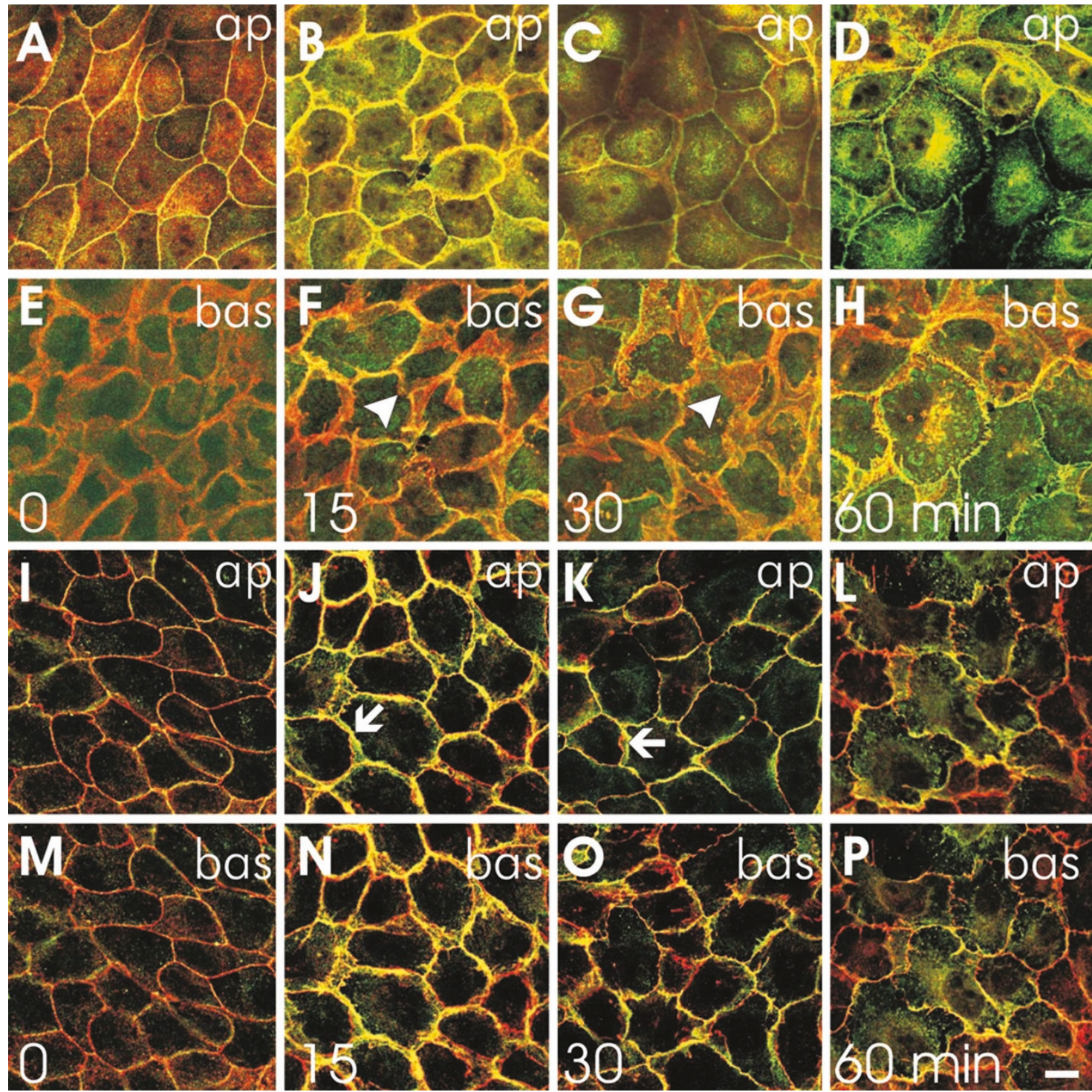

Figure 1.

Confocal images showing the colocalization of E-cadherin $(\mathrm{A}$ to $\mathrm{H}$ ) or tight junctional component ZO-1 (I to P) with antiphosphotyrosine antibody in various time points (0-60 minutes) after shifting the ts-Src Madin-Darby canine kidney (MDCK) cells to permissive temperature $35^{\circ} \mathrm{C}$. E-cadherin and ZO-1 are seen in red, antiphosphotyrosine in green, and their colocalization in yellow. The distance between apical level (A to D, I to $L$ ) and basal level (E to $H, M$ to $P$ ) is approximately $1.5 \mu \mathrm{m}$. Within 15 minutes, the cell-cell contacts start opening, large cadherin clusters are seen at the basal surfaces (arrowhead in F, G), and the cells are flattened ZO-1 is in two pools, alone and colocalizing with antiphosphotyrosine antibody (arrow in J, K). It remains, however, close to lateral membranes. Ap, apical, bas, basal focal layers. Bar, $10 \mu \mathrm{m}$.

during the 60-minute follow-up (Fig. 4, Q and R). Similar results were obtained when the intracellular $\mathrm{pH}$ was lowered to $\mathrm{pH}$ 5.5. (Fig. 4, S and T). In these circumstances, formation of early endosomes is allowed, but transport of endosomal compartments toward the cell center is blocked, which results in an accumulation of the lipids beneath the plasma membrane (Cosson et al, 1989; Eskelinen et al, 1991). Very clearly, mobilization of cadherin and actin seem to be the functional target of activated Src kinase.

\section{Protein Phosphorylation in MDCK Cells after Activation of Src Kinase}

The phosphorylation levels of proteins that seemed to colocalize with antiphosphotyrosine antibody in immu- nofluorescence stainings were analyzed by immunoprecipitation with specific antibodies and immunoblotting with antiphosphotyrosine (Table 1 and Fig. 3). At nonpermissive temperature, $\beta$-catenin was weakly phosphorylated in a soluble fraction of Src-MDCK cells, whereas soluble fractions of $\mathrm{p} 120^{\mathrm{ctn}}$, E-cadherin, ZO-1, occludin, claudin, and moesin were also phosphorylated within 15 to 30 minutes at $35^{\circ} \mathrm{C}$ (Fig. 3 and Table 1).

In the literature, it has been documented that $\beta$-catenin, ZO- 1 , and $\mathrm{p} 120^{\mathrm{ctn}}$ are significantly tyrosinephosphorylated in a time-dependent manner after the activation of Src kinase in Src-transformed MDCK cells (Aghib and McCrea, 1995; Behrens et al, 1993; Takeda et al, 1995). In these experiments, immunoprecipitation was carried out with antiphosphotyrosine antibody and 


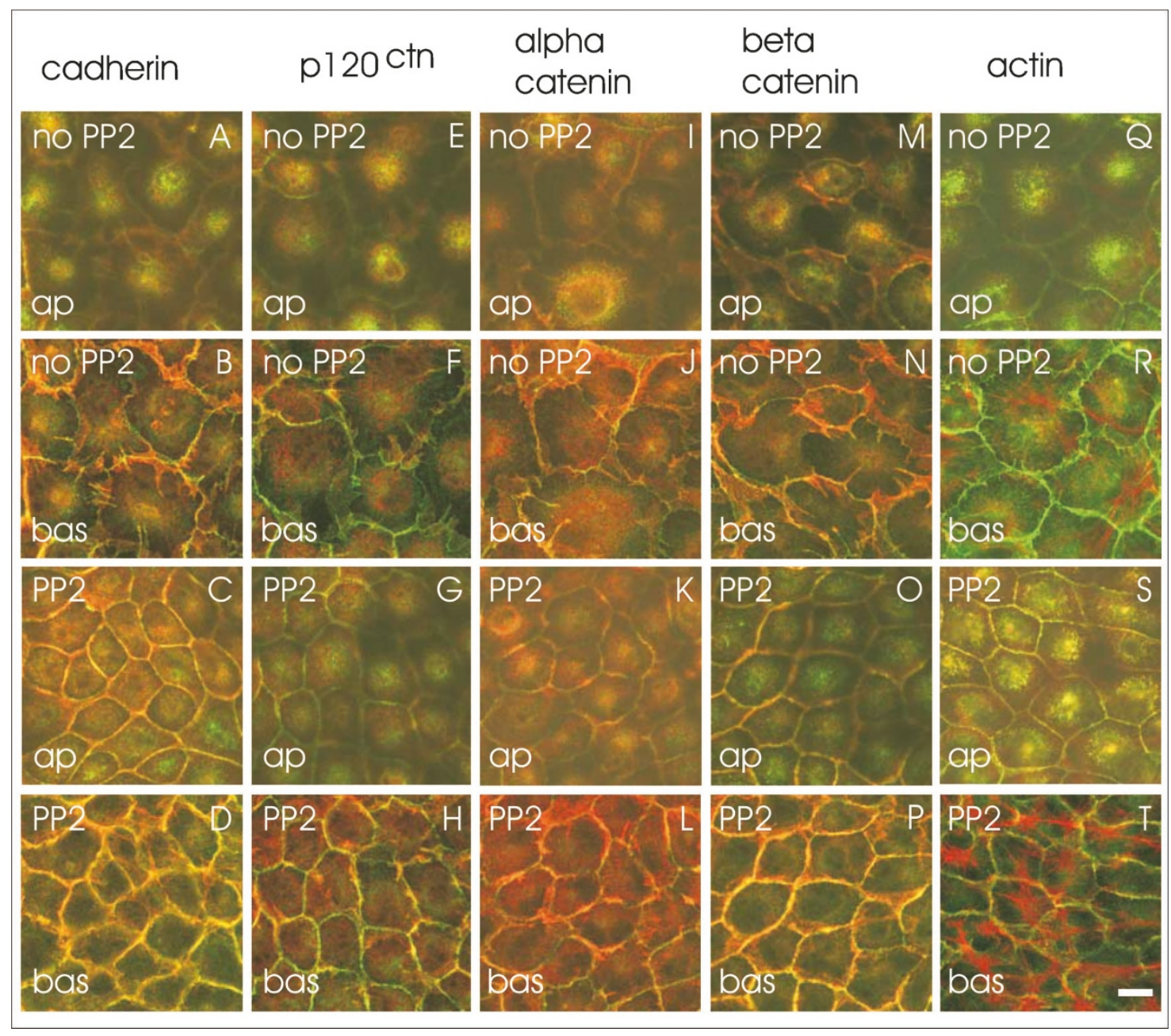

Figure 2.

Confocal images showing the colocalization of antiphosphotyrosine antibody with cadherin (A to D), p120 $0^{\text {ctn }}(\mathrm{E}$ to $\mathrm{H}), \alpha$-catenin (I to $\mathrm{L}$ ), $\beta$-catenin (M to $\mathrm{P}$ ), and actin $(\mathrm{Q}$ to $\mathrm{T})$ in ts-Src MDCK cells incubated for 120 minutes at permissive temperature without PP2 $\left(35^{\circ} \mathrm{C}, \mathrm{A}, \mathrm{B}, \mathrm{E}, \mathrm{F}, \mathrm{I}, \mathrm{J}, \mathrm{M}, \mathrm{N}, \mathrm{Q}, \mathrm{R}\right)$ or first for 15 minutes at nonpermissive temperature and thereafter for 120 minutes at $35^{\circ} \mathrm{C}$ in the presence of $50 \mu \mathrm{mPP} 2(\mathrm{C}, \mathrm{D}, \mathrm{G}, \mathrm{H}, \mathrm{K}, \mathrm{L}, \mathrm{O}, \mathrm{P}, \mathrm{S}, \mathrm{T})$. Antiphosphotyrosine staining is seen in green, other proteins in red, and their colocalization in yellow. The distance between apical level and basal level is approximately $1.5 \mu \mathrm{m}$. For $120 \mathrm{minutes}$ at $35^{\circ} \mathrm{C}$, cadherin, $\mathrm{p} 120^{\mathrm{ctn}}, \alpha$-catenin, and tyrosine phosphorylated proteins are hardly visible at apical junctions (A, E, I). At basal surfaces, cadherin, $\mathrm{p} 120^{\mathrm{ctn}}, \alpha$-, and $\beta$-catenin are in large cluster partially alone, partially colocalized with antiphosphotyrosine antibodies (B, F, J, N). Membranous actin staining was decreased, and actin stress fibers were gathered to the basal surface of the cells $(\mathrm{R})$. Treatment of the cells with $50 \mu \mathrm{M}$ PP2 restored the cubic morphology of the cells and returned cadherin, $\alpha$, and $\beta$-catenin back to apical junctions (C, K, 0$)$. In contrast, there was very little $\mathrm{p} 120^{\mathrm{ctn}}$ or actin at lateral membranes $(\mathrm{G}, \mathrm{S})$. p120 $0^{\mathrm{ctn}}$ and clusters of short actin filaments were mostly visible at the basal side of the cells $(H, T)$. ap, apical, bas, basal focal layers. Bar, $10 \mu \mathrm{m}$.

immunoblotting with specific antibodies. This method is susceptible to coprecipitation of nonphosphorylated proteins. We tested this by performing the immunoprecipitation process in both ways. In the case where we precipitated the proteins with antiphosphotyrosine antibodies, the specific antibodies detected more tyrosinephosphorylated proteins on blot than they did after precipitation with specific antibodies and blot with antiphosphotyrosine antibodies (data not shown). Precipitation of proteins with specific antibodies and subsequent analysis of their tyrosine staining on blot seemed to be a reliable method, but the intensity of the phosphorylated band on blot was also dependent on the affinity of the antiphosphotyrosine antibody. In our study, polyclonal antiphosphotyrosine gave no signal or only a weak signal on blot, whereas monoclonal antiphosphotyrosine clearly detected very low levels of phosphorylation.
The only protein whose shift to cytoplasm correlated with its phosphorylation was $\mathrm{p} 120^{\mathrm{ctn}}$. After 120 minutes of incubation at $35^{\circ} \mathrm{C}$, both a soluble and insoluble fraction of $\mathrm{p} 120^{\mathrm{ctn}}$ were heavily phosphorylated, and inhibition of v-Src by PP2 diminished the intensity on blot to $64 \%$ of the one without the inhibitor (Fig. 3). It is known that $\mathrm{p} 120^{\mathrm{ctn}}$ is a strong substrate of Src with eight tyrosine residues (Mariner et al, 2001). Most likely, PP2 cannot inhibit all of the phosphorylation reactions because it has been shown that approximately $35 \%$ of Src activity still remains after 1 hour of incubation of Src with PP2 in HT29 cells (Nam et al, 2002).

\section{Reformation of AJs in Src-MDCK Cells after Shift from $35^{\circ} \mathrm{C}$ to $40.5^{\circ} \mathrm{C}$}

Our results showed that activation of Src kinase resulted in simultaneous disintegration of AJs and 
Table 1. Tyrosine Phosphorylation of Junctional Proteins in Src-MDCK Cells Grown Either at $40.5^{\circ} \mathrm{C}$ or After Shift to $35^{\circ} \mathrm{C}$ for 30 Minutes

\begin{tabular}{|c|c|c|c|c|}
\hline \multirow{2}{*}{$\begin{array}{l}\text { Immunoprecipitated } \\
\text { Protein }\end{array}$} & \multicolumn{2}{|c|}{ src-MDCK Cells $40.5^{\circ} \mathrm{C}$} & \multicolumn{2}{|c|}{ src-MDCK Cells $35^{\circ} \mathrm{C} 30 \mathrm{~min}$} \\
\hline & $\mathrm{s}$ & $\mathrm{p}$ & $\mathrm{s}$ & $\mathrm{p}$ \\
\hline ZO-1 & - & - & + & - \\
\hline$\beta$-catenin & + & - & + & - \\
\hline E-cadherin & $+1-$ & - & $+1-$ & - \\
\hline $\mathrm{p} 120^{\mathrm{ctn}}$ & - & - & + & - \\
\hline Occludin & - & - & + & - \\
\hline Claudin & - & - & + & - \\
\hline Moesin & - & - & + & - \\
\hline
\end{tabular}

- , no phosphorylation; +/-, hardly detectable phosphorylation; +, detectable phosphorylation.

Tyrosine phosphorylation of ZO-1, $\beta$-catenin, E-cadherin, p120ctn, occludin, claudin, and moesin in Src-MDCK cells grown either at $40.5^{\circ} \mathrm{C}$ for 24 hours or at $40.5^{\circ} \mathrm{C}$ for 24 hours and transferred thereafter to $35^{\circ} \mathrm{C}$ for $30 \mathrm{~min}$. The soluble $(\mathrm{s})$ and insoluble $(\mathrm{p})$ fractions of the cells were immunoprecipitated with anti-ZO-1, anti- $\beta$-catenin, anti-E-cadherin, anti-p120ctn, occludin, claudin, and moesin antibodies coupled to protein G-Sepharose beads, and phosphorylation was detected on blot by anti-phosphotyrosine antibodies. In Src-MDCK cells, $\beta$-catenin was already phosphorylated at $40.5^{\circ} \mathrm{C}$, whereas no signs of phosphorylation were detected in other specimens. The shift of temperature to $35^{\circ} \mathrm{C}$ for 30 min. induced tyrosine phosphorylation of Z0-1, p120 ctn occludin, claudin, and moesin.

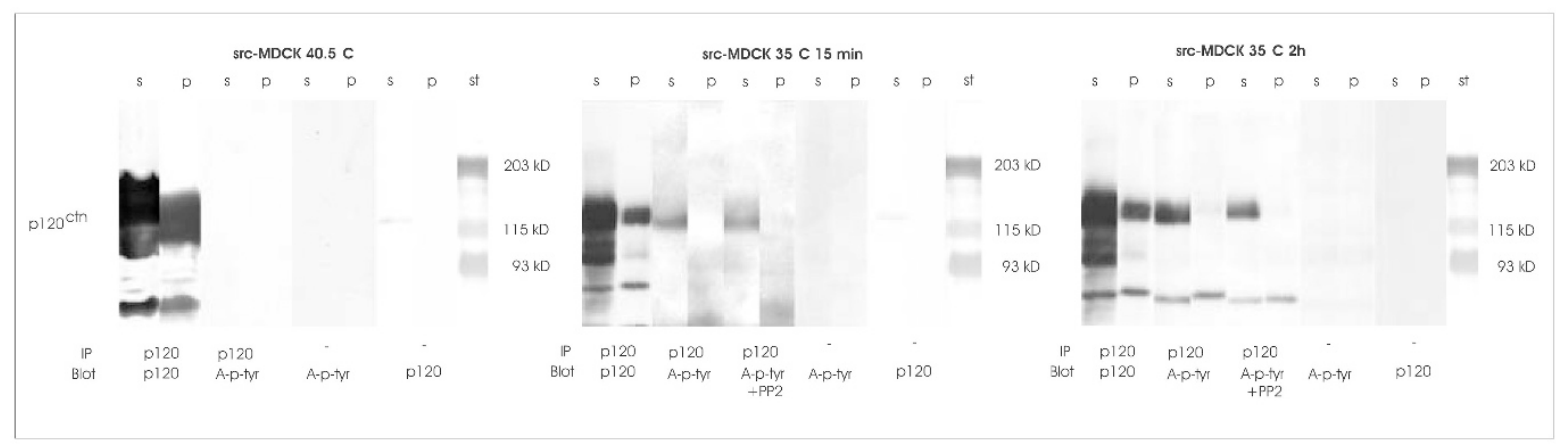

Figure 3.

Immunoblot analysis showing Src-induced phosphorylation of $\mathrm{p} 120^{\mathrm{ctn}}$ in soluble (s) and cytoskeletal (p) fractions of Src-transformed MDCK cells grown for 24 hours at $40.5^{\circ} \mathrm{C}$ and lysed immediately or incubated thereafter for 15 minutes or 120 minutes at $35^{\circ} \mathrm{C}$ with or without $50 \mu \mathrm{m}$ PP2. Proteins were immunoprecipitated with anti-p120ctn antibody coupled to BSA-blocked protein G-Sepharose beads, and the precipitation ability of anti-p120 ctn antibody was tested by staining the precipitate with the same antibody on blot. Phosphorylation of the precipitate was detected on Western blot by antiphosphotyrosine antibodies. The samples without immunoprecipitation show the unspecific binding of tyrosine-phosphorylated proteins and $\mathrm{p} 120^{\text {ctn }}$ to the BSA-blocked protein G-Sepharose beads tested by antiphosphotyrosine and anti-p120 ctn antibodies. p120 ctn was unphosphorylated at $40.5^{\circ} \mathrm{C}$, whereas a soluble fraction of p120 ctn was clearly phosphorylated in Src-MDCK cells shifted to $35^{\circ} \mathrm{C}$ for 15 minutes and 120 minutes. In cells incubated for 120 minutes at $35^{\circ} \mathrm{C}$, inhibition of Src by PP2 diminished the phosphorylation level of $120^{\text {ctn }}$ to $64 \%$ of the one without inhibitor. A very small amount of soluble p120 ctn bound unspecifically to blocked Sepharose beads in Src-MDCK cells, but this fraction was not tyrosine phosphorylated.

formation of stress fibers. This does not give us information about the mutual role of actin, cadherin, or $\mathrm{p} 120^{\mathrm{ctn}}$ in the maintenance of cell-cell junctions, however. To analyze the movement of these proteins more carefully, we cultivated the Src-MDCK cells at permissive temperature, shifted them to nonpermissive temperature for short time periods, and monitored the behavior of actin, p120 $\mathrm{ctn}$, and cadherin (Fig. 4). At $35^{\circ} \mathrm{C}$, actin bundles were seen at the basal surface of the cells, and cadherin was found in cytoplasmic vesicles (Fig. 4, A and E) and $\mathrm{p} 120^{\mathrm{ctn}}$ in cytoplasm (data not shown). Already, in 15 minutes at nonpermissive temperature, when Src expression was downregulated, a portion of the cadherin was seen at the lateral membranes, and the number of actin fibers was diminished. In 60 minutes at $40.5^{\circ} \mathrm{C}$, cadherin was returned to lateral membranes, and only a few vesicles remained in cytoplasm, whereas actin fibers had practically vanished (Fig. 4, C and G). Actin reappeared 1 hour later at the lateral membranes (Fig. 4, D and H), whereas $\mathrm{p} 120^{\mathrm{ctn}}$ was still seen in the cytoplasm after 2 hours of incubation at $40.5^{\circ} \mathrm{C}$ (Fig. 4, D and $\mathrm{H}$ ), and it took approximately 4 hours before it returned to the lateral membranes (data not shown). Therefore, it seems that, in the process of rebuilding the AJs, cadherin is the pioneer. The cadherin shift was clearly dependent on an intact tubulin network because incubation of the cells at $40.5^{\circ} \mathrm{C}$ in the presence of nocodazole slowed the process, and in 60 minutes at nonpermissive temperature, there was much less cadherin at the membranes than without nocodazole, and actin bundles were still present at the basal surface (Fig. 4, I to $\mathrm{K}$ and $\mathrm{M}$ to $\mathrm{O}$ ).

\section{Distribution of Actin and Junctional Proteins in Tiam-1 Src-MDCK Cells}

It is well known that the degree of polymerization of actin filaments is regulated by small GTPases, tyrosine kinases being part of the signaling pathway both 
From 35 to $40 \mathrm{C}$, no nocodazole

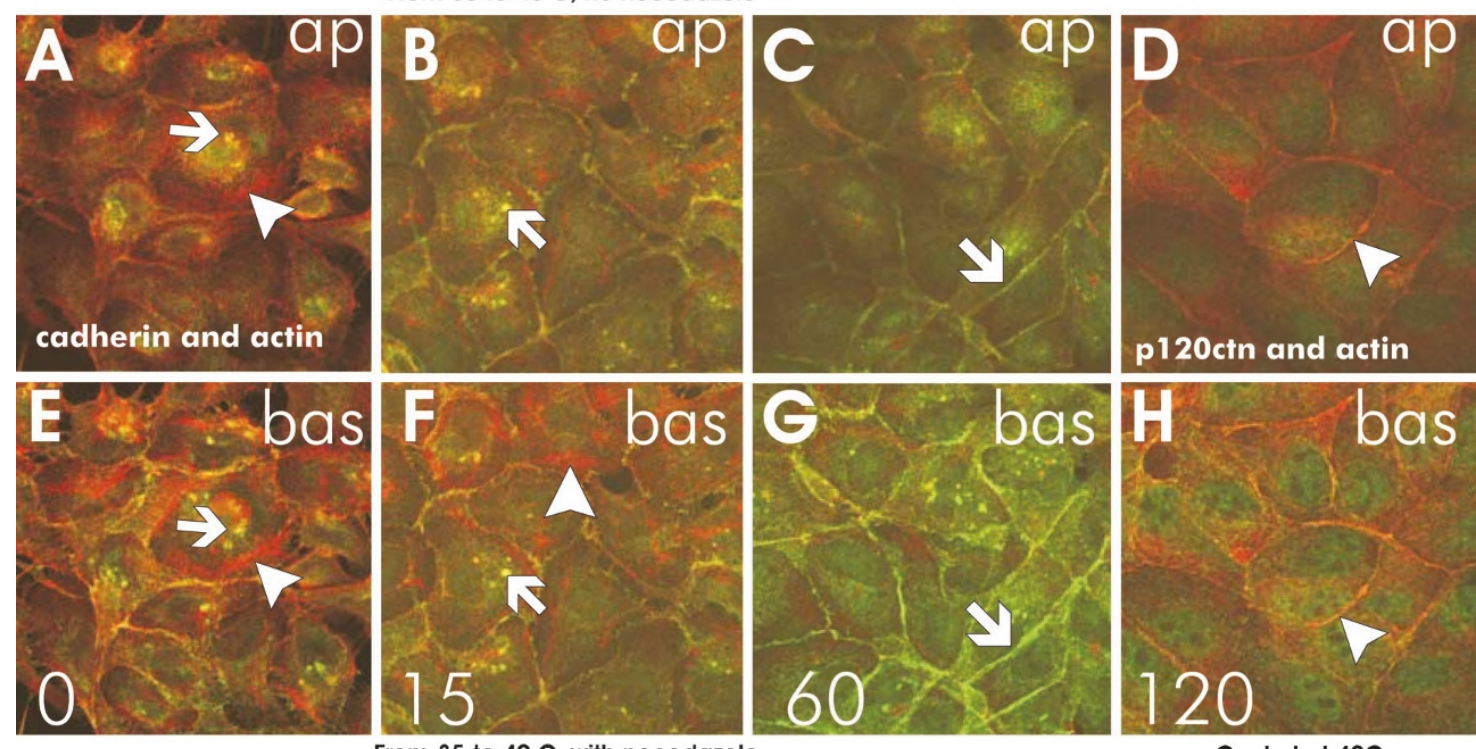

From 35 to $40 \mathrm{C}$, with nocodazole
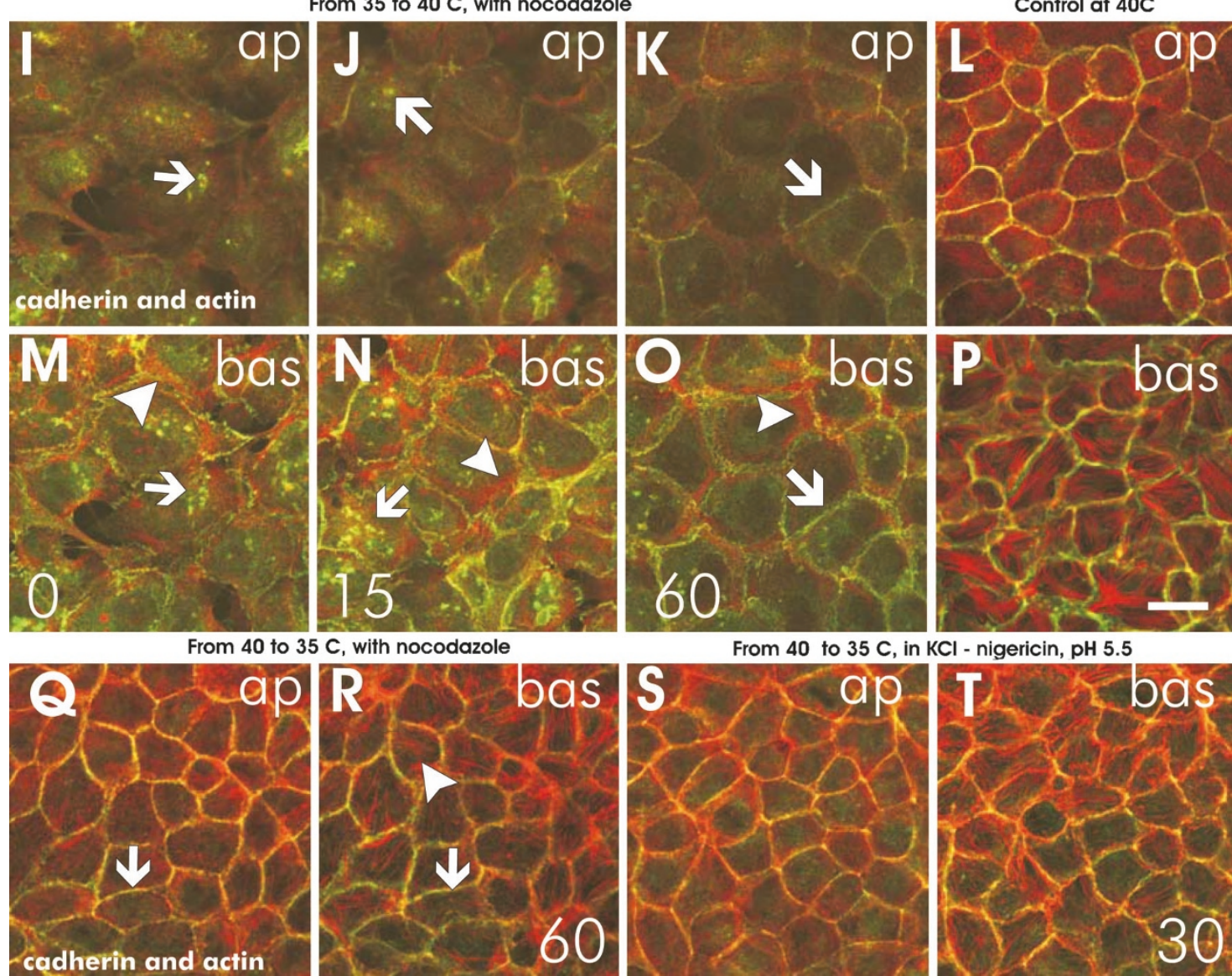

From 40 to $35 \mathrm{C}$, in $\mathrm{KCl}$ - nigericin, $\mathrm{pH} 5.5$

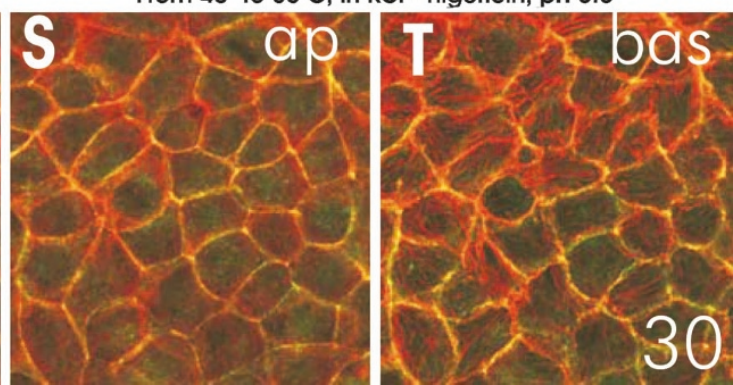

Figure 4.

Confocal images showing colocalization of actin with cadherin ( $A$ to $C, E$ to $G, I$ to $T)$ and actin with $p 120^{\text {ctn }}$ (D, H) at various time points $(0-120$ minutes) after shifting ts-Src MDCK cells from $35^{\circ} \mathrm{C}$ to $40.5^{\circ} \mathrm{C}$ (A to $\mathrm{K}, \mathrm{M}$ to $\mathrm{O}$ ) or from $40.5^{\circ} \mathrm{C}$ to $35^{\circ} \mathrm{C}(\mathrm{Q}$ to T) without nocodazole $(\mathrm{A}$ to $\mathrm{H}$ ) and in the presence of $5 \mu \mathrm{g} / \mathrm{ml}$ nocodazole (I to K, M to 0, Q, R) or in KCl-nigericin buffer at pH 5.5 (S, T). The control cells grown constantly at $40.5^{\circ} \mathrm{C}$ are shown (L, P). Actin, visualized by Alexa 568 phalloidin, is seen in red, cadherin and $p 120^{c t n}$ in green, and their colocalization in yellow. The distance between apical level ( $\mathrm{A}$ to $\mathrm{D}, \mathrm{I}$ to $\left.\mathrm{L}, \mathrm{Q}, \mathrm{S}\right)$ and basal level $(\mathrm{E}$ to $\mathrm{H}, \mathrm{M}$ to $\mathrm{P}, \mathrm{R}, \mathrm{T})$ is approximately $1.5 \mu \mathrm{m}$. At $35^{\circ} \mathrm{C}$, cadherin was in intracellular vesicles and returned back to cell membranes within 1 hour after the shift to $40.5^{\circ} \mathrm{C}($ arrows in $A$ to $C, E$ to $G$ ), whereas actin gathered in bundles (arrowheads in $A, E, F$ ), which vanished, and actin returned back to basal membranes after 2 hours of incubation at $40.5^{\circ} \mathrm{C}$ (arrowheads in D, H). p120 ctn was hardly visible in the cytoplasm (H). Nocodazole treatment increased the number of cadherin vesicles (arrows in I, J, $\mathrm{M}, \mathrm{N}$ ) but could not prevent its return to lateral membranes after shift to $40.5^{\circ} \mathrm{C}$ (arrows in $\mathrm{K}, 0$ ). Nocodazole treatment also prolonged the existence of actin bundles at $40.5^{\circ} \mathrm{C}$ (arrowheads in $\mathrm{N}, 0$ ). In cells shifted from $40.5^{\circ} \mathrm{C}$ to $35^{\circ} \mathrm{C}$ in the presence of nocodazole, both actin and cadherin remained at lateral membranes (arrows in $Q$ and $R$ ), and stress fibers were short and few (arrowhead in R). In the same way, lowering of intracellular pH to 5.5 inhibited the epithelial-mesenchymal transition at $35^{\circ} \mathrm{C}$, and the cells remained similar to those grown at $40.5^{\circ} \mathrm{C}(\mathrm{S}, \mathrm{T}$ and $\mathrm{L}, \mathrm{P}) . \mathrm{Bar}, 10 \mu \mathrm{m}$. 
upstream and downstream from the Rho family GTPases (Abram and Courtneidge, 2000). Therefore, we repeated the experiments using Tiam-1-transfected Src-MDCK cells and monitored the cell behavior in the short time intervals after activation of Src (Fig. 5). Contrary to Src-transformed MDCK-cells, the morphology of Tiam-1 Src-MDCK cells remained normal after the shift to permissive temperature (Fig. 5). Instead of clustering to basal surfaces, cadherin accumulated to lateral membranes and in this way supported the cubic morphology of Tiam-1 Src-MDCK cells. Also, $\mathrm{p} 120^{\mathrm{ctn}}$ and $\mathrm{ZO}-1$ remained at the membranes, although their distribution was widened (Fig.
5 , J and N). Surprisingly, the number of actin filaments increased at the basal surfaces at permissive temperature in the same way as in Src-transformed MDCK cells (Fig. 5, F, G, and H). Thus, it seems that Tiam-1 can antagonize the epithelial-mesenchymal transition induced by Src kinase but not the formation of stress fibers.

To confirm that the effects of Tiam-1 expression are indeed transmitted by way of Rac- 1 activity, we microinjected dominant inactive Rac GTPase into the Tiam-1 Src-MDCK cells grown at $40.5^{\circ} \mathrm{C}$ and then shifted them to $35^{\circ} \mathrm{C}$. The results are shown in Figure 5. In microinjected cells, cadherin and p120 ${ }^{\mathrm{ctn}}$ ap-
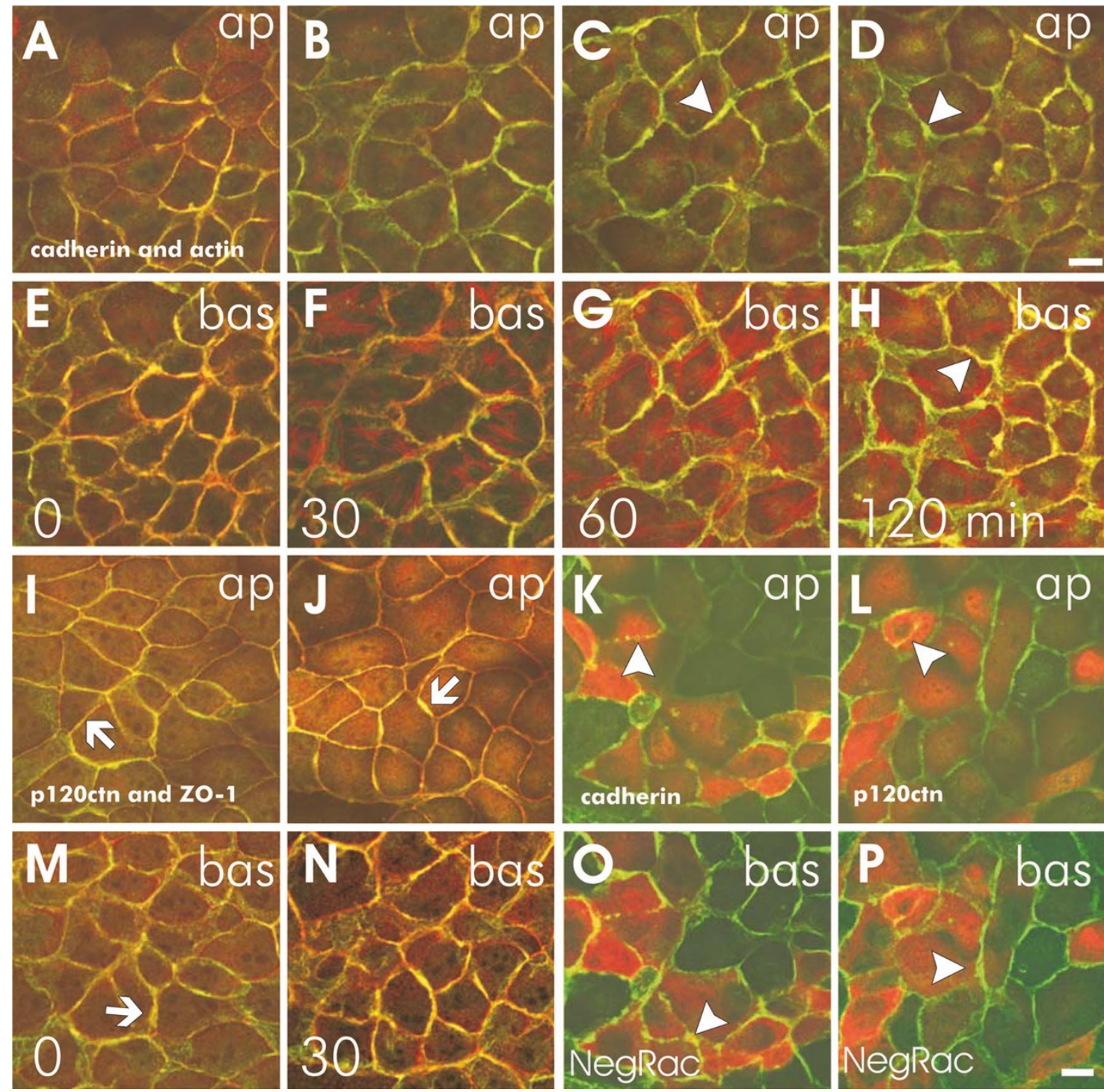

Figure 5.

Confocal images showing colocalization of actin with cadherin $(\mathrm{A}$ to $\mathrm{H})$ and p120ctn with ZO-1 (I, M and J, N) in various time points (0-120 minutes) after shifting Tiam-1 ts-Src MDCK cells from $40.5^{\circ} \mathrm{C}$ to $35^{\circ} \mathrm{C}$. Actin, visualized by Alexa 568 phalloidin and Z0-1, are seen in red, cadherin and p120 ctn in green, and their colocalization in yellow. The distance between apical level ( $A$ to $D, I$ to $\mathrm{J}$ ) and basal level ( $E$ to $\mathrm{H}, \mathrm{M}, \mathrm{N}$ ) is approximately $1.5 \mu \mathrm{m}$. The behavior of cadherin differed completely from Src-MDCK cells shown in Figure 1: instead of clustering to basal surfaces, cadherin accumulated to lateral membranes (arrowheads in C, D, H). Also, p120 ctn colocalized with ZO-1 at lateral membranes at $40.5^{\circ} \mathrm{C}$ and remained there for a short time interval at $35^{\circ} \mathrm{C} \mathrm{(arrow} \mathrm{in} \mathrm{I,} \mathrm{J,} \mathrm{M).} \mathrm{Confocal} \mathrm{images} \mathrm{showing} \mathrm{the}$ distribution of cadherin (K, 0) and p120 ctn $(\mathrm{L}, \mathrm{P})$ in Tiam-1 Src-MDCK cells injected with a mixture of inactive Rac and Texas Red anti-rabbit antibody followed by incubation at permissive temperature $\left(35^{\circ} \mathrm{C}\right)$ for 120 minutes. Red color shows the microinjected cells, and green staining shows distribution of cadherin and p120 $0^{\mathrm{ctn}}$. The distance between apical level and basal level is approximately $1.4 \mu \mathrm{m}(\mathrm{K}, 0)$ and $1.1 \mu \mathrm{m}(\mathrm{L}, \mathrm{P})$. Inactive Rac induced discontinuous staining pattern of cadherin and $120^{\mathrm{ctn}}$ at the apical side of the cells (arrowhead in K, L) and clustering of proteins to the basal side of the cells (arrowhead in 0, P). ap, apical, bas, basal focal layers. Bar, $10 \mu \mathrm{m}$. 
peared in discontinuous bands at the short lateral walls as well as in cytoplasmic clusters (arrows in Fig. 5, K, O, L, and P). Therefore, the cells microinjected with inactive Rac had the mesenchymal phenotype induced by Src activation. All in all, it seems that cadherin is the protein that rapidly reacts both to expression and shutting down of Src kinase. Internalization of cadherin can be inhibited by PP2, nocodazole, and Tiam-1. Formation of stress fibers and, therefore, activation of Rho seems to correlate with tyrosine phosphorylation of $\mathrm{p} 120^{\mathrm{ctn}}$.

\section{Effect of Tiam-1 on the Formation of Apico-Basal Axis in the Three-Dimensional Environment}

Normal MDCK cells form a polarized cell cyst in collagen, in mixtures of laminin and collagen, as well as in the rich environment of Matrigel (Rahikkala et al, 2001). Src sensitizes the MDCK cells to extracellular matrix, and, in three-dimensional environment at permissive temperature, Src-transformed MDCK cells form an irregular cluster in collagen I, invasive extensions in the mixture of laminin and collagen I, and a polarized cell cyst in Matrigel (Rahikkala et al, 2001). Tiam-1 is known to induce invasion of lymphoma cells and suppress invasion of Ras-transformed MDCK cells to collagen (Hordijk et al, 1997) and, thus, has a different effect in different cell types and environments. To elucidate the effect of Rac on cadherin in three-dimensional gels, we studied the effect of Tiam-1 on the differentiation of MDCK cells in various matrices. For that purpose, Tiam-1 Src-MDCK cells were cultured in three-dimensional gels at nonpermissive temperature where Src is inhibited but Tiam-1 is active. In collagen I or in the laminin-collagen I mixture, Tiam-1 MDCK cells formed an irregular cluster, with some signs of lumen but without a clear apicobasal axis (Fig. 6, A and B). In contrast, in Matrigel, they formed a perfect cell cyst with a clear lumen (Fig. 6C). In growth factor-depleted Matrigel, the cells formed a nondifferentiated cluster, and the cells were filled with vacuoles and often went to apoptosis (Fig. 6 , D and $H$ ). Thus, contrary with untransformed MDCK cells, it seems that Tiam-1-transfected cells are sensitive to their environment and differentiation is possible only in a rich environment containing both growth factors and basal lamina components. At permissive temperature, Tiam-1 Src-MDCK cells always formed an irregular cell cluster (data not shown), and thus Tiam-1 expression could not prevent the deleterious effect of Src on cell polarity in a three-dimensional environment. There is a possibility that Src transformation might even affect the cell differentiation at nonpermissive temperature. Therefore, we carried out control experiments with Src-MDCK cells at various environments at $40.5^{\circ} \mathrm{C}$ (Fig. 6, I to L). The cell phenotype was very similar to Tiam-1 Src-MDCK cells, except in the growth factor-reduced Matrigel, where Src-MDCK cells survived and grew in nondifferentiated clusters, whereas Tiam-1 Src-MDCK cells went to apoptosis (Fig. 6, D, H, and L). Therefore, Tiam-1 makes the MDCK cells susceptible to apopto- sis in environments having basal lamina components but lacking growth factors.

To elucidate the role of growth factors in Matrigel in the differentiation process, we cultivated the SrcMDCK cells and Tiam-1 Src-MDCK cells at nonpermissive temperature in growth factor-depleted Matrigel supplemented with Matrigel-conditioned medium, cholera toxin, and platelet-derived growth factor (PDGF) (Fig. 6, E to G, M, O, P). Cholera toxin and PDGF stimulated differentiation and induced formation of perfectly polarized cell cysts with clear lumens and thick cadherin walls (Fig. 6, E to G, M). We also studied Tiam-1 in these circumstances (Fig. 6, N to P). In Src-MDCK cells grown in growth factor-reduced Matrigel without PDGF, Tiam-1 was diffuse in cytoplasm, even apically, whereas in cells grown in the presence of PDGF, Tiam-1 was located at the lateral membranes of differentiated cell cysts of both SrcMDCK and Tiam-1 Src-MDCK cells (Fig. 6, G, P, M, and 0 ). It appears that Tiam-1 and cadherin are recruited to lateral membranes simultaneously during the formation of an apico-basal axis and the lumens of MDCK cells.

The structure of cell-cell contacts in Tiam-1 SrcMDCK cells in three-dimensional environments was further studied by immunoelectron microscopy (Fig. 7). The cells grown in collagen or Matrigel at nonpermissive temperature were stained with anti-Ecadherin and anti-p120 ${ }^{\mathrm{ctn}}$ antibodies. In cells grown in collagen, cadherin was seen along the cell-cell junction sites (Fig. 7A), whereas $\mathrm{p} 120^{\mathrm{ctn}}$ remained in the cytoplasmic site of the junctional structure (Fig. 7B). In cells grown in Matrigel, cell-cell contacts were clearly observed, cadherin was seen along the adherent junction and between the adjacent cells (Fig. 7C), and p120 ${ }^{\mathrm{ctn}}$ shifted to the junctional structures close to the plasma membrane (Fig. 7D). Therefore, p120 ctn may have a role in supporting tight cell adhesion and formation of clear apico-basal axis.

\section{Discussion}

Epithelium-mesenchyme transition is an important event during morphogenetic processes in embryos, whereas scattering of epithelial cells in adult tissues plays a crucial role in the malignant transformation, carcinoma cell invasion, and metastasis. Src family kinases are required for cell division, they are enriched at cell adhesion sites, and the viral mutant v-Src is an active player in signaling cascades, leading to malignant transformation of cells (Frame et al, 2002). The mechanisms by which Src kinases exert their functions are still debated. Three hypotheses have emerged. First, Src activity may affect specific substrates, either cytoskeletal components or signaling molecules located in cell-cell and cell-substrate adhesion sites, which then, tyrosine-phosphorylated, will modify the cellular architecture. Second, Src activity may interact with the Ras signaling pathway. Third, Src may also generate a unique pathway leading to activation of specific transcription factors (Boyer et al, 1997; Frame et al, 2002). 


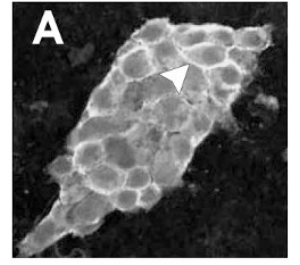

collagen

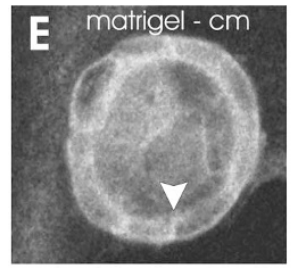

depleted matrigel

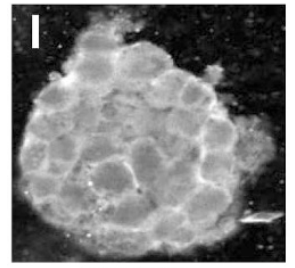

collagen

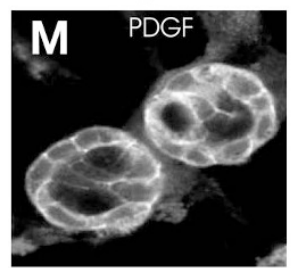

depleted matrigel

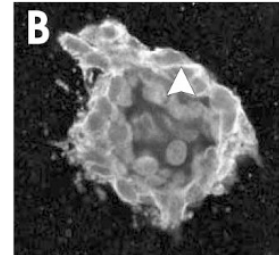

collagen and laminin
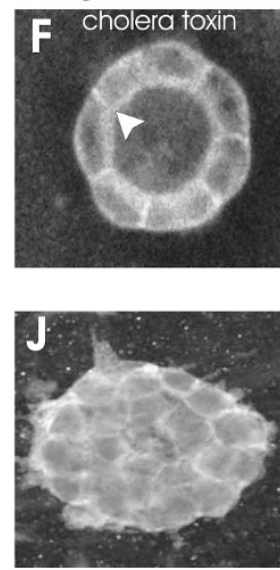

collagen and laminin

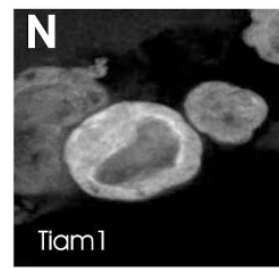

depleted matrigel

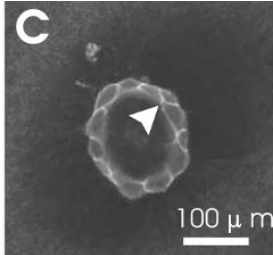

matrigel
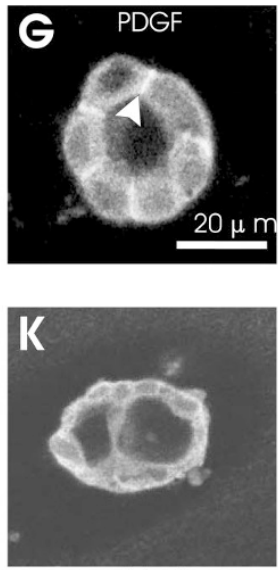

matrigel

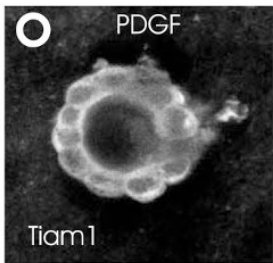

depleted matrigel

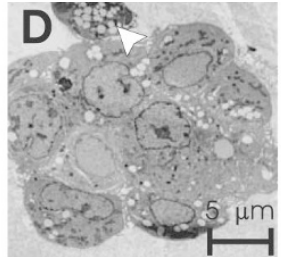

depleted matrigel

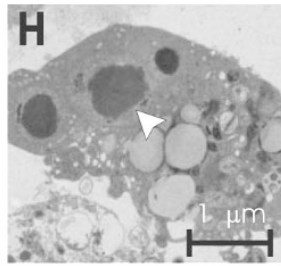

depleted matrigel

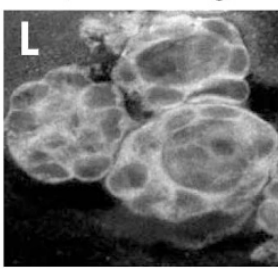

depleted matrigel

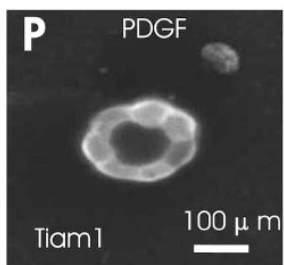

depleted matrigel

Figure 6.

Confocal images showing the distribution of cadherin in $x-y$ sections of Tiam-1 Src-MDCK cells grown in collagen I (A), in a mixture of collagen I and laminin (B), in Matrigel $(C)$, or in growth factor-depleted Matrigel supplemented with Matrigel-conditioned medium (E), cholera toxin (F), and PDGF (G) at nonpermissive temperature $40.5^{\circ} \mathrm{C}$. The cells grew in a nonpolarized cluster in collagen I (A) but began to form a lumen in the mixture of laminin and collagen I (B) and formed a complete cell cyst with a clear lumen in Matrigel $(C)$ or in growth factor-depleted Matrigel with supplements (E to $G$ ). There are signs of invasive extensions in collagen and laminin. Cadherin is delineating the cell-cell contact sites in all these environments (arrowheads). Bar, $100 \mu \mathrm{m}$ or $20 \mu \mathrm{m}$. Transmission electron micrographs of Tiam-1 Src-MDCK cells grown at nonpermissive temperature $40.5^{\circ} \mathrm{C}$ in growth factor-depleted Matrigel without supplements (D, $\mathrm{H}$ ). The cells were filled with vacuoles and often went to apoptosis. Bar, $5 \mu \mathrm{m}(\mathrm{D})$ and $1 \mu \mathrm{m}(\mathrm{H})$. Distribution of cadherin in Src-MDCK cells grown in collagen I (I), in a mixture of collagen I and laminin $(\mathrm{J})$, in Matrigel $(\mathrm{K})$, or in growth factor-depleted Matrigel without $(\mathrm{L})$ or in the presence of PDGF $(\mathrm{M})$ at nonpermissive temperature $40.5^{\circ} \mathrm{C}$. In contrast with Tiam-1 Src-MDCK cells, Src-MDCK cells grew in growth factor-depleted Matrigel in irregular clusters with cadherin in cytoplasm (L). PDGF treatment improved the polarity and recruited cadherin to lateral membranes (M). The distribution of Tiam-1 in x-y sections of Src-MDCK cells (N, 0) or Tiam-1 Src-MDCK cells $(\mathrm{P})$ grown in growth factor-depleted Matrigel without $(\mathrm{N})$ or supplemented with PDGF $(0, \mathrm{P})$ at nonpermissive temperature. Tiam-1 is located at lateral membranes in the presence or PDGF $(0, P)$ and colocalizes with cadherin $(G, P$ and $M, 0)$. Bar, $100 \mu \mathrm{m}$.

The ts-Src-transformed MDCK cells designed by Behrens et al (1993) is an excellent model in the studies of the effects of tyrosine phosphorylation on the integrity of an epithelium because the activation of Src kinase can be triggered simply by lowering the ambient temperature. We took advantage of this and carefully analyzed the distribution and phosphorylation of junctional components in short time intervals after the shift to permissive temperature. The existing information on the mobility of the components of the cell-cell junctions caused by increased phosphorylation is obtained using vanadate-treated cells (Collares-Buzato et al, 1998; Volberg et al, 1992). Within 30 minutes of the treatment of MDCK cells with a phosphotyrosine phosphatase inhibitor, vanadate, the AJs and associated actin were deteriorated, whereas vinculin containing focal contacts and stress fibers became abundant, although desmosomes and ZO-1 distribution were not significantly affected (Volberg et al, 1992). In these experiments, the earliest detectable effect was the dissociation of the junctional actin bundle from the membrane, without apparent splitting of the junctions themselves, and the authors suggested that the primary target for the vanadateinduced effects is the actin cytoskeleton and not the junctional proteins. Analogous results have been obtained by Collares-Buzato et al (1998), in which a redistribution of actin, E-cadherin, and $\mathrm{ZO}-1$ in 30 minutes occurred under the exposure of vanadate to MDCK cells. Our results are well in line with these observations.

In ts-Src-transformed MDCK cells, it has been observed that tyrosine phosphorylation levels of $\beta$-catenin, ZO-1, and ERM (ezrin/radixin/moesin) pro- 

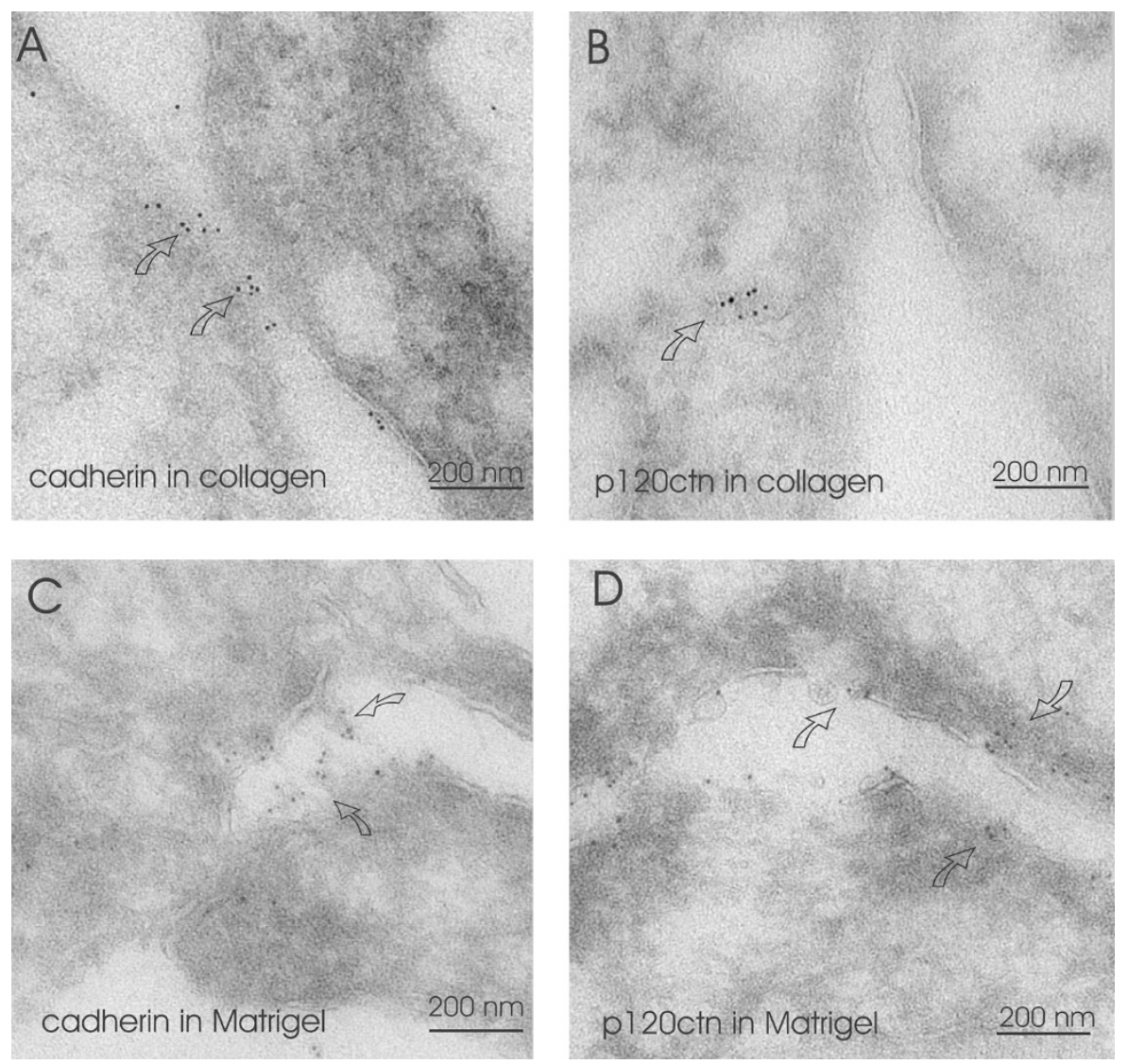

\section{Figure 7}

Immunoelectron micrographs showing labeling of cadherin $(A, C)$ and $p 120^{\text {ctn }}(B, D)$ in Tiam-1 Src-MDCK cells grown in collagen (A, B) and Matrigel (C, D) at nonpermissive temperature. In the cells grown in collagen, cadherin is seen along the cell-cell junction sites $(A)$, whereas p120 ctn stays in the cytoplasmic site of the junctional structure (B). In Matrigel, well-developed cell-cell contacts are formed where cadherin is seen along the adherent junction and between the cells (C). Also, $\mathrm{p} 120^{\mathrm{ctn}}$ is located in the junctional structure close to the plasma membrane (D). Bar, $200 \mathrm{~nm}$.

teins have increased after the shift to permissive temperature, whereas $\alpha$-catenin and E-cadherin are unphosphorylated (Takeda et al, 1995). The consequences of the phosphorylation of these proteins by Src kinases are still controversial. It has been shown that tyrosine phosphorylation of $\beta$-catenin in $L$ fibroblasts is not required for the strong-to-weak state shift of cadherin-based adhesion (Takeda et al, 1995). Neither did tyrosine phosphorylation affect the stability or stoichiometry of E-cadherin forming complexes with $\beta$-catenin, $\alpha$-catenin, and p120 ctn (Papkoff, 1997). The role of junctional proteins in the loss of cell adhesion has been even more complicated by the results of Nieman et al (1999), which show that cell motility and invasiveness correlates better with the expression of $\mathrm{N}$-cadherin rather than with the loss of E-cadherin. Our results gave a clear correlation between phosphorylation of soluble p120 ${ }^{\mathrm{ctn}}$ fraction and its translocation from cell-cell contact sites. Concomitantly, all components of AJs were translocated to the basal surface. In line with our results, Ras-transformed breast epithelial MCF10-A cells reveal elevated p120 ${ }^{\text {ctn }}$ phosphorylation on tyrosine, loosening of AJs, and, interestingly, increased association of p120 ctn with cadherin (Kinch et al, 1995). The fact that epithelial morphology of Src-MDCK cells was restored in the presence of Src inhibitor PP2 even if $\mathrm{p} 120^{\mathrm{ctn}}$ was partially phosphorylated and translocated in cytoplasm shows that other proteins are responsible for epithelial phenotype in a two-dimensional environment. We conclude that tyrosine phosphorylation of one single component of AJs is not responsible for epithelial-mesenchymal transition of Src-transformed MDCK cells.

The rapid return of cadherin to the lateral membranes of Src-MDCK cells after the shift from $35^{\circ} \mathrm{C}$ to $40.5^{\circ} \mathrm{C}$ clearly shows that cadherin is the key protein in cell adhesion. There is accumulating evidence that E-cadherin is a dynamic protein and not permanently incorporated into stable junctional complexes. Instead, even at a steady state in confluent monolayers of MDCK cells, at least one pool of surface E-cadherin remains subject to endocytosis and is recycled to the cell surface by way of a postGolgi endocomal pathway (Le et al, 1999). Palacios and his coworkers (2001, 2002) have observed that ARF6-GTPase controls the endocytosis of E-cadherin: in MDCK cells transfected with the constitutively activated form of ARF6GTPase, E-cadherin, and $\beta$-catenin translocated to basal ruffles similarly to that we observed after the shift of Src-transformed MDCK cells to the permissive temperature. Expression of a dominant-negative 
ARF6 mutant, in turn, inhibited both scatter factorinduced and $\mathrm{v}$-Src-induced disintegration of AJs in MDCK cells (Palacios et al, 2001). Thus, activation of ARF6 is downstream of v-Src activation during the disassembly of AJs. In our experiments, nocodazole completely blocked the disassembly of AJs of ts-Src MDCK cells after shift to permissive temperature. This showed that tubulin-mediated vesicle transport of cadherin is required for the epithelial-mesenchymal transition of MDCK cells during Src activation. Lowering of intracellular $\mathrm{pH}$ is known to inhibit endocytosis at the level of early endosomes (Cosson et al, 1989; Eskelinen et al, 1991). Also, this treatment completely blocked the Src-induced disassembly of AJs, showing that not only tubulin-mediated vesicle transport but also invagination of membranes is a prerequisite for Src action. Most likely, there are several steps in membrane transport where Src might interfere in the process.

The shift of Src-MDCK cells to permissive temperature seemed to induce concomitant depolymerization of membranous actin and formation of stress fibers to basal surface of the cells. Because Rho activity is a prerequisite for formation of stress fibers, activation of Src likely stimulates activation of Rho GTPase in a very short time interval after its expression at $35^{\circ} \mathrm{C}$. In Ras-transformed MDCK cells, it has been shown that oncogenic Ras down-regulates Rac activity and up-regulates Rho activity, leading to epithelial-mesenchymal transition caused by downregulation of expression of Tiam-1, an RacGEF (Zondag et al, 2000). In contrast, reconstitution of Rac activity in these cells down-regulated Rho activity and restored the epithelial phenotype (Zondag et al, 2000). The effect of Src on Rac activity in epithelial cells has not been analyzed in detail. We used Tiam-1transfected ts-Src MDCK cells as a model to elucidate the mutual relationships of Rac, Rho, and Src in MDCK cells. The morphology and protein distribution of Tiam-1 Src-MDCK cells at $40.5^{\circ} \mathrm{C}$ was indistinguishable from Src-transformed or untransformed MDCK cells. A shift to permissive temperature brought about some but not all changes seen in Srctransformed cells: the cell morphology remained cubic, and cadherin accumulated at lateral membranes, whereas stress fibers were still present at the basal surface. Therefore, there was no mutual relationship between Rac and Rho activity. Apparently, Src is an upstream regulator of Rho, inducing formation of stress fibers independently of Tiam-1 action. Anastasiadis and Reynolds (2000) have shown that p120 ctn can inhibit activation of Rho. Although there is not data on the role of tyrosine phosphorylation on the functionality of $\mathrm{p} 120^{\mathrm{ctn}}$, it is tempting to speculate that its phosphorylation might abolish its inhibitory activity, leading to increased Rho activity and formation of stress fibers in Src-transfected MDCK cells after the shift to permissive temperature.

It has been shown in several studies that Rac-1 recruits cadherin to lateral membranes (Hordijk et al, 1997; Takaishi et al, 1997). The mechanism by which this is achieved is not known, and there is even an inverse correlation between activation of ARF-6 and Rac-1 in MDCK cells (Palacios et al, 2002). This is because of the recruitment of a nucleoside phosphate (NDP) kinase, Nm23-H1, to the cell-cell contacts by ARF- 6 activation and consequent inhibition of Tiam-1. Because the cell morphology remained cubic in MDCK cells double transfected with v-Src and Tiam-1 at permissive temperature, over-expression of Tiam-1 seemed to overcome the effect of ARF-6 in cells with an endogenous level of ARF- 6 and promoted cadherin accumulation to the lateral membranes. We studied the retransport of cadherin in ts-Src MDCK cells grown at $35^{\circ} \mathrm{C}$ by monitoring the mesenchymalepithelial transition of the cells after the shift to $+40.5^{\circ} \mathrm{C}$. This caused very rapid accumulation of cadherin to lateral membranes followed by restoration of the cubic morphology, whereas actin and $\mathrm{p} 120^{\mathrm{ctn}}$ followed several hours afterward. The process was delayed by nocodazole treatment. Thus, tubulinmediated transport of cadherin seems also to be a crucial step in reformation of epithelial cells.

In a three-dimensional environment, the cell behavior is more complex because of integrin-cadherin cross-talk, and the cells may express either undifferentiated or differentiated phenotype and show invasive properties. MDCK cells grown both in collagen I and in Matrigel form a cyst with the apical surface facing the lumen (Rahikkala et al, 2001). When transfected with inactive Rac-1, the MDCK cells exhibit an inversion of apical pole at the cyst periphery (O'Brien et al, 2001). The authors suggest that this is because of a missassembly of laminin caused by diminished $\alpha_{3} \beta_{1}$ integrin level because exogenous laminin restored proper apical reorientation. In contrast, the expression of constitutively active Rac-1 did not significantly alter MDCK cyst morphogenesis in collagen I (O'Brien et al, 2001). In our experiments, an RacGEF, Tiam-1, promoted differentiation and formation of an apico-basal axis of MDCK cells in Matrigel but not in collagen or in a collagen-laminin mixture. Therefore, Tiam-1-transfected MDCK cells seemed to be more sensitive to the environment than MDCK cells transfected with constitutively active Rac-1, and laminin was not sufficient to induce their differentiation. Even such a rich matrix mixture as growth factor-depleted Matrigel, which only lacks the major growth factor components of Matrigel, was not sufficient to induce polarized phenotype, but the cells went to apoptosis. Matrigel-conditioned medium rescued the polarized morphology, indicating that soluble factors in Matrigel were responsible for the formation of an apico-basal axis of Tiam-1-transfected cells. More specifically, PDGF, a Rac activator and cholera toxin, an activator of heterotrimeric $G$ proteins, restored the differentiated morphology and membranous cadherin accumulation in cells cultivated in growth factor-depleted Matrigel. In these circumstances, Tiam-1 was also located at lateral membranes. Tiam-1 has several distinct domains and binding partners, which are well described by Mertens et al (2003). Membrane translocation of Tiam-1 is crucial for its capacity to induce Rac-mediated membrane ruffles and activation of $c$ 
Jun N-terminal kinase. The first integral membrane protein reported to directly interact with Tiam-1 is the hyaluronic acid receptor isoform $\mathrm{CD} 44_{\mathrm{v} 3}$, and the same domain of Tiam-1 also interacts with ankyrin (Mertens et al, 2003). These interactions might be involved in the complex processes of apoptosis and differentiation of MDCK cells where Tiam-1 and PDGF seem to play an active role.

In summary, it seems that in Src-activated MDCK cells in short time intervals, cadherin endocytosis is the main target of Src, which is counteracted by Tiam-1 by some mechanism. In a three-dimensional environment during long-term incubation, an assembly of cadherin and $\mathrm{p} 120^{\mathrm{ctn}}$ are regulated by Tiam-1 but are under control of soluble external stimuli.

\section{Materials and Methods}

\section{Cell Culture}

The ts-Src MDCK cells were provided by Professor Walter Birchmeier and Dr. Jürgen Behrens (Max Delbrück Center for Molecular Medicine, Berlin, Germany) (Behrens et al, 1993). These cells, transformed with a temperature-sensitive mutant of v-Src, exhibit an epithelial phenotype at the nonpermissive temperature for expression of v-Src kinase $\left(40.5^{\circ} \mathrm{C}\right)$, but acquire a more fibroblast-like morphology after culture at the permissive temperature of $35^{\circ} \mathrm{C}$ (Behrens et al, 1993; Sormunen et al, 1999). ts-Src transformed MDCK cells (originally from Dr. Behrens) carrying a C1199 Tiam-1 neoconstruct were obtained from Professor John Collard (The Netherlands Cancer Institute, Division of Cell Biology, Amsterdam, The Netherlands) (Habets et al, 1995). Both cell lines were cultivated in cell culture dishes and in three-dimensional collagen, laminin and Matrigel, and growth factor depleted-Matrigel mixtures, as described by Sormunen et al (1999) and Rahikkala et al (2001).

\section{Antibodies and Other Reagents}

Anti- $\beta$-catenin mouse mAb (C19220) and anti-p120 ctn mouse mAb (P17920) were purchased from Transduction Laboratories (Lexington, Kentucky). Antiphosphotyrosine rabbit pAb (06-427) was from UBI (Upstate Biotechnology, Lake Placid, New York) and antiphosphotyrosine mouse mAb (clone PT-66) was from Sigma (St. Louis, Missouri). MDCK-specific anticadherin mouse mAb (rr1) was purchased from Developmental Studies Hybridoma Bank (lowa City, lowa) and anti-ZO-1 rat mAb was obtained from Chemicon International Incorporated (Temecula, California). Anticlaudin rabbit $\mathrm{pAb}(71-7800)$ and antioccludin rabbit pAb (71-1500) were purchased from Zymed (Carlton Court, South San Francisco, California). Anti- $\alpha$ catenin mouse mAb (IG5) was provided by Professors Keith Johnson and Margaret J. Wheelock (Nebraska Medical Center, Omaha, Nebraska). Antimoesin rat mAb (M22) was a gift from Professors Shoichiro and Sachiko Tsukita (Kyoto, Japan). Polyclonal Tiam-1 antibody was a kind gift of Professor John Collard (The Netherlands Cancer Institute, Division of Cell Biology,
Amsterdam, The Netherlands). Alexa 488 and Alexa 568 phalloidins, Alexa 488 and Alexa 546 goat antimouse or anti-rabbit antibodies, and Texas Red antimouse antibody were from Molecular Probes (Eugene, Oregon). Tetramethylrhodamine-conjugated anti-rat antibody was from Chemicon. Peroxidase-conjugated anti-mouse and anti-rat immunoglobulins were purchased from DAKO (Glostrup, Denmark). Peroxidaseconjugated anti-rabbit Ig was from Sigma and rabbit anti-mouse IgG from Zymed. Luminol and p-coumaric acid were from Sigma. The inhibitor of Src kinase, PP2, was purchased from Calbiochem (La Jolla, California). It was dissolved in dimethyl sulfoxide in a concentration of $10 \mathrm{~mm}$ and used for experiments in a concentration of $50 \mu \mathrm{M}$ (Brandt et al, 2002). Inactive RacGTPase was purchased from Cytoskeleton (Denver, Colorado), dissolved in distilled water to a concentration of $1 \mathrm{mg} / \mathrm{ml}$, and diluted to $100 \mu \mathrm{g} / \mathrm{ml}$ in 100 $\mathrm{mm} \mathrm{KCl}, 5$ mм HEPES, pH 7.25 (Palovuori and Eskelinen, 2000). Nocodazole was purchased from Calbiochem, dissolved in dimethyl sulfoxide in a concentration of $1 \mathrm{mg} / \mathrm{ml}$, and diluted in HBSS (HBSS, Gibco) at a concentration of $5 \mu \mathrm{g} / \mathrm{ml}$. Cholera toxin was purchased from BIOMOL Research Laboratories (Plymouth Meeting, Pennsylvania), dissolved in sterile distilled water in concentration $1.0 \mathrm{mg} / \mathrm{ml}$, and diluted in cell culture medium at a concentration of $2 \mathrm{ng} / \mathrm{ml}$. PDGF was purchased from R\&D Systems, Incorporated (Minneapolis, Minnesota), dissolved in $4 \mathrm{mM} \mathrm{HCl}$ containing $0.1 \%$ BSA at a concentration of $10 \mu \mathrm{g} / \mathrm{ml}$, and diluted to medium to a concentration of $10 \mathrm{ng} / \mathrm{ml}$. The cytoplasm of the cells was acidified with $5 \mu \mathrm{M}$ nigericin in isotonic $\mathrm{KCl}$ buffer $(140 \mathrm{mM} \mathrm{KCl}, 2 \mathrm{~mm}$ $\mathrm{CaCl}_{2}, 1 \mathrm{~mm} \mathrm{MgCl}_{2}, 0.5 \mathrm{~mm} \mathrm{K \textrm {H } _ { 2 }} \mathrm{PO}_{4}, 20 \mathrm{~mm}$ HEPES, $\mathrm{pH} 5.5$ ) at $37^{\circ} \mathrm{C}$ for a given time period (Eskelinen et al, 1991).

\section{Immunostaining for Confocal Fluorescence Microscopy}

The fixation protocols were as follows: (a) 4\% formaldehyde in a cytoskeleton-stabilizing Pipes-EGTA$\mathrm{MgCl}_{2}$ (PEM) buffer (100 mм piperazine diethanesulfonic acid, $5 \mathrm{~mm}$ EGTA, $2 \mathrm{~mm} \mathrm{MgCl}_{2}, \mathrm{pH}$ 6.8) containing $0.2 \%$ Triton $\mathrm{X}-100$ for 10 minutes at room temperature and postfixation with methanol for 5 minutes at $-20^{\circ} \mathrm{C}$ for double stainings of antiphosphotyrosine antibodies with anti- $\alpha$-catenin, anti- $\beta$ catenin, anticadherin ( $r r 1)$, and anti-p120 ${ }^{\mathrm{ctn}}$ antibodies and for double stainings with anti-ZO-1 with antip120 ctn antibodies; (b) methanol for 10 minutes at $-20^{\circ} \mathrm{C}$ for double stainings of antiphoshotyrosine antibodies with anti-ZO-1 antibody; and (c) 1\% formaldehyde in PBS $\left(0.01 \mathrm{M} \mathrm{NaH}_{2} \mathrm{PO}_{4} / \mathrm{Na}_{2} \mathrm{HPO}_{4}, 145 \mathrm{~mm}\right.$ $\mathrm{NaCl}, \mathrm{pH}$ 7.2) for 15 minutes at room temperature followed by $0.2 \%$ Triton $\mathrm{X}-100$ for 15 minutes at room temperature for double stainings of anticlaudin with antiphosphotyrosine. For mutual colocalization analysis of cadherin or $\mathrm{p} 120^{\mathrm{ctn}}$ with phalloidin, the cells were fixed in $4 \%$ formaldehyde and $0.2 \%$ Triton X-100 in PEM buffer for 10 minutes at room temperature followed by postfixation in ethanol for a few seconds at $-20^{\circ} \mathrm{C}$. After fixation, the cells were washed briefly 
with $\mathrm{NaCl}$-HEPES buffer $(140 \mathrm{~mm} \mathrm{NaCl}, 10 \mathrm{~mm}$ HEPES, pH 7.0) and incubated with primary antibodies and thereafter with secondary antibodies diluted in $\mathrm{NaCl}-\mathrm{HEPES}$ buffer. After washings, the cells were mounted in an Immu-Mount mounting liquid (Shandon, Pittsburgh, Pennsylvania). The cells grown in three-dimensional gels for 6 to 7 days were fixed and stained in situ for localization of cadherin and Tiam-1 as described earlier by Rahikkala et al (2001).

\section{Confocal Fluorescence Microscopy}

The specimens were viewed by Zeiss 510 confocal laser scanning microscope (Jena, Germany) equipped with an argon laser (488 nm) and HeNe laser (543 nm) and by using a $\times 63$ objective as described earlier (Palovuori and Eskelinen, 2000; Rahikkala et al, 2001). Optical sections of the specimens were generated through the cell by scanning with $0.36 \mu \mathrm{m}$ intervals and by using a 505 to $530 \mathrm{~nm}$ band pass filter for the green emission and a 560 or $630 \mathrm{~nm}$ low-pass filter for the red emission channel.

\section{Immunoprecipitation of Tyrosine Phosphorylated Proteins}

For immunoprecipitation and immunoblotting analysis, ts-Src MDCK cells were lysed directly after 24 hours culture at $40.5^{\circ} \mathrm{C}$ or after subsequent shift to $35^{\circ} \mathrm{C}$ for 15,30 , or 120 minutes in the presence or absence of $50 \mu \mathrm{M}$ PP2. For immunoprecipitation, the insoluble and soluble fractions were first preincubated by rotating with $30 \mu \mathrm{l}$ of GammaBind G Sepharose beads (Amersham Pharmacia Biotech AB, Uppsala, Sweden). Thereafter, the supernatants were incubated with $40 \mu \mathrm{l}$ of G-Sepharose beads coated with 1 to 2 $\mu \mathrm{g}$ of the precipitating antibody (anti-p120 ${ }^{\mathrm{ctn}}$, antiZO- 1 , anti- $\alpha$ and anti- $\beta$-catenin, anticadherin, antioccludin and anticlaudin, and antimoesin antibodies) and blocked with $10 \%$ BSA. After overnight immunoprecipitation at $4^{\circ} \mathrm{C}$, the beads were washed three times with $1 \mathrm{ml}$ of radioimmunoprecipitation assay buffer and boiled in $40 \mu$ l of SDS sample buffer.

\section{Immunoblotting}

The ability of $\mathrm{p} 120^{\mathrm{ctn}}, \mathrm{ZO}-1, \alpha$ - and $\beta$-catenin, cadherin, occludin, claudin, and moesin antibodies to precipitate was tested by staining the precipitates on blots with corresponding antibodies. Their phosphorylation status was analyzed with the aid of polyclonal and monoclonal antiphosphotyrosine antibodies from UBI and Sigma, respectively. The precipitated proteins were resolved on 7.5\% SDS-PAGE and immunostained on nitrocellulose membrane. After blocking with 3\% nonfat dry milk in PBS $0.05 \%$ Tween-20 (PBS-T-MLK), the blot was incubated with the primary antibody overnight at $4^{\circ} \mathrm{C}$ followed by incubation with horseradish peroxidase-conjugated secondary antibody for 1.5 hours at room temperature. The washings were made with water and with PBS-T. The blot was developed with luminol-coumaric acid detection solution (875 $\mu \mathrm{M}$ luminol, $135 \mu \mathrm{M}$ p-coumaric acid, and $0.01 \% \mathrm{H}_{2} \mathrm{O}_{2}$ in $0.1 \mathrm{M}$ Tris- $\mathrm{HCl} \mathrm{pH} \mathrm{8.5)} \mathrm{for} 2$ minutes and exposed to Hyperfilm ECL x-ray film (RPN 3103K, Amersham Pharmacia Biotech, Buckinghamshire, England). The intensities of the bands were compared with the aid of Metamorph image processing software (Universal Imaging Corporation, Downingtown, Pennsylvania).

\section{Microinjection of Inactive Rac}

Microinjections were carried out using an Eppendorf micromanipulator 5171 and microinjector 5246 (Hamburg, Germany) installed on an Axiovert $405 \mathrm{M}$ inverted microscope with a heating stage (Zeiss, Oberkochen, Germany) as described earlier (Palovuori and Eskelinen, 2000). Typically, all of the cells within one or two squares of the etched cover slips were injected within a time period of 10 to 30 minutes for each experiment. To keep the intracellular $\mathrm{pH}$ normal during the injection at normal atmosphere, the cells were transferred to Medium 199 with Hanks' salts and 25 mм Hepes (Gibco Invitrogen Ltd, Paisley, United Kingdom). Inactive RacGTPase $(100 \mu \mathrm{g} / \mathrm{ml})$ was microinjected into Tiam-1 Src-MDCK cells grown at $40.5^{\circ} \mathrm{C}$ together with Texas Red anti-rabbit antibody $(0.7 \mathrm{mg} / \mathrm{ml})$ as a marker for injected cells. After injection, the cells were returned to culture medium to the cell culture stove. The cells were fixed after 2 hours of incubation at $35^{\circ} \mathrm{C}$ and stained for cadherin and p120 ctn.

\section{Transmission Electron Microscopy}

Tiam-1 Src-MDCK cells were processed for transmission electron microscopy as described by Rahikkala et al (2001). The specimens were examined with a Philips CM100 transmission electron microscope.

\section{Immunoelectron Microscopy}

For immunolabelling, Tiam-1 Src-MDCK cells grown in three-dimensional gels were first incubated for 60 minutes in the enzyme mixture Matrisperse (Becton Dickinson, San Jose, California) that softened and partially dissolved the extracellular matrix gel. Thereafter, the gel was centrifuged for 5 minutes at $1000 \mathrm{~g}$ to pack the cell cysts to a close pellet. The cell pellet was then fixed in $4 \%$ paraformaldehyde for 1 hour, immersed in 2.3 M sucrose, and frozen in liquid nitrogen. The ultrathin cryosections, cut with a Leica Ultracut UCT microtome (Wetzlar, Germany), were incubated in 5\% BSA and with $0.1 \%$ coldwater fish skin gelatin (Aurion, Wageningen, The Netherlands) in PBS. Thereafter the sections were incubated with anti-E-cadherin or anti-p120 ${ }^{\mathrm{ctn}}$ antibodies, washed, and exposed to rabbit anti-mouse lgG (Zymed) and protein A-gold complex (5 nm) (Slot and Geuze, 1985). The sections were embedded in methylcellulose and examined in a Philips CM100 transmission electron microscope.

\section{Acknowledgements}

Professors Keith Johnson and Margaret Wheelock (Nebraska Medical Center, Omaha, Nebraska) are 
kindly acknowledged for providing the $\alpha$-catenin antibody (clone Ig5), Professor Walter Birchmeier and Dr. Jürgen Behrens (Max Delbrück Center for Molecular Medicine, Berlin, Germany) for providing the ts-Srctransformed MDCK cells, and Professor John Collard (The Netherlands Cancer Institute, Division of Cell Biology, Amsterdam, the Netherlands) for providing the Tiam-1 transfected ts-Src MDCK cells and Tiam-1 antibody. Professors Shoichiro and Sachiko Tsukita (Kyoto, Japan) are kindly acknowledged for providing anti-moesin antibody. The authors thank Ms. Sirpa Kellokumpu, Ms. Marja-Liisa Martti, Ms. Marja Tolppanen, and Mr. Hannu Wäänänen for their skilful technical assistance.

\section{References}

Abram CL and Courtneidge SA (2000). Src family tyrosine kinases and growth factor signaling. Exp Cell Res 254:1-13.

Aghib DF and McCrea PD (1995). The E-cadherin complex contains the src substrate p120. Exp Cell Res 218:359-369.

Anastasiadis PZ, Moon SY, Thoreson MA, Mariner DJ, Crawford HC, Zheng Y, and Reynolds AB (2000). Inhibition of RhoA by p120 catenin. Nat Cell Biol 2:637-644.

Anastasiadis PZ and Reynolds AB (2000). The p120 catenin family: Complex roles in adhesion, signaling and cancer. J Cell Sci 113(Pt 8):1319-1334.

Behrens J, Vakaet L, Friis R, Winterhager E, Van Roy F, Mareel MM, and Birchmeier W (1993). Loss of epithelial differentiation and gain of invasiveness correlates with tyrosine phosphorylation of the E-cadherin/beta-catenin complex in cells transformed with a temperature-sensitive v-SRC gene. J Cell Biol 120:757-766.

Boyer B, Roche S, Denoyelle M, and Thiery JP (1997). Src and Ras are involved in separate pathways in epithelial cell scattering. EMBO J 16:5904-5913.

Brandt D, Gimona M, Hillmann M, Haller $\mathrm{H}$, and Mischak $\mathrm{H}$ (2002). Protein kinase $C$ induces actin reorganization via a Src- and Rho-dependent pathway. J Biol Chem 277:2090320910.

Collares-Buzato CB, Jepson MA, Simmons NL, and Hirst BH (1998). Increased tyrosine phosphorylation causes redistribution of adherens junction and tight junction proteins and perturbs paracellular barrier function in MDCK epithelia. Eur J Cell Biol 76:85-92.

Cosson P, deCurtis I, Pouyssegur J, Griffiths G, and Davoust $\mathrm{J}$ (1989). Low cytoplasmic $\mathrm{pH}$ inhibits endocytosis and transport from the trans-Golgi network to the cell surface. J Cell Biol 108:377-387.

Eskelinen S, Kok JW, Sormunen R, and Hoekstra D (1991). Coated endosomal vesicles: sorting and recycling compartment for transferrin in BHK cells. Eur J Cell Biol 56:210-222.

Frame MC, Fincham VJ, Carragher NO, and Wyke JA (2002). v-Src's hold over actin and cell adhesions. Nat Rev Mol Cell Biol 3:233-245.

Fujita Y, Krause G, Scheffner M, Zechner D, Leddy HE, Behrens J, Sommer T, and Birchmeier W (2002). Hakai, a c-Cbl-like protein, ubiquitinates and induces endocytosis of the E-cadherin complex. Nat Cell Biol 4:222-231.
Fukata M, Nakagawa M, Kuroda S, and Kaibuchi K (1999). Cell adhesion and Rho small GTPases. J Cell Sci 112(Pt 24):4491-4500.

Giancotti FG (1997). Integrin signaling: Specificity and control of cell survival and cell cycle progression. Curr Opin Cell Biol 9:691-700.

Habets GG, van der Kammen RA, Stam JC, Michiels F, and Collard JG (1995). Sequence of the human invasion-inducing TIAM1 gene, its conservation in evolution and its expression in tumor cell lines of different tissue origin. Oncogene 10: 1371-1376.

Hordijk PL, ten Klooster JP, van der Kammen RA, Michiels F, Oomen LC, and Collard JG (1997). Inhibition of invasion of epithelial cells by Tiam1-Rac signaling. Science 278:14641466 .

Kaibuchi K, Kuroda S, and Amano M (1999). Regulation of the cytoskeleton and cell adhesion by the Rho family GTPases in mammalian cells. Ann Rev Biochem 68:459-486.

Kinch MS, Clark GJ, Der CJ, and Burridge K (1995). Tyrosine phosphorylation regulates the adhesions of ras-transformed breast epithelia. J Cell Biol 130:461-471.

Le TL, Yap AS, and Stow JL (1999). Recycling of E-cadherin: a potential mechanism for regulating cadherin dynamics. J Cell Biol 146:219-232.

Mariner DJ, Anastasiadis P, Keilhack H, Bohmer FD, Wang J, and Reynolds AB (2001). Identification of Src phosphorylation sites in the catenin p120ctn. J Biol Chem 276:2800628013.

Mertens AE, Roovers RC, and Collard JG (2003). Regulation of Tiam1-Rac signaling. FEBS Lett 546:11-16.

Nam JS, Ino Y, Sakamoto M, and Hirohashi S (2002). Src family kinase inhibitor PP2 restores the E-cadherin/catenin cell adhesion system in human cancer cells and reduces cancer metastasis. Clin Cancer Res 8:2430-2436.

Nieman MT, Prudoff RS, Johnson KR, and Wheelock MJ (1999). N-cadherin promotes motility in human breast cancer cells regardless of their E-cadherin expression. J Cell Biol 147:631-644.

O'Brien LE, Jou TS, Pollack AL, Zhang Q, Hansen SH, Yurchenco P, and Mostov KE (2001). Rac1 orientates epithelial apical polarity through effects on basolateral laminin assembly. Nat Cell Biol 3:831-838.

Palacios F, Price L, Schweitzer J, Collard JG, and D'SouzaSchorey C (2001). An essential role for ARF6-regulated membrane traffic in adherens junction turnover and epithelial cell migration. EMBO J 20:4973-4986.

Palacios F, Schweitzer JK, Boshans RL, and D'SouzaSchorey C (2002). ARF6-GTP recruits Nm23-H1 to facilitate dynamin-mediated endocytosis during adherens junctions disassembly. Nat Cell Biol 4:929-936.

Palovuori R and Eskelinen S (2000). Role of vinculin in the maintenance of cell-cell contacts in kidney epithelial MDBK cells. Eur J Cell Biol 79:961-974.

Papkoff J (1997). Regulation of complexed and free catenin pools by distinct mechanisms. Differential effects of Wnt-1 and v-Src. J Biol Chem 272:4536-4543.

Perl AK, Wilgenbus P, Dahl U, Semb H, and Christofori G (1998). A causal role for E-cadherin in the transition from adenoma to carcinoma. Nature 392:190-193. 
Rahikkala M, Sormunen R, and Eskelinen S (2001). Effects of src kinase and TGFbeta1 on the differentiation and morphogenesis of MDCK cells grown in three-dimensional collagen and Matrigel environments. J Pathol 195:391-400.

Sander EE, ten Klooster JP, van Delft S, van der Kammen RA, and Collard JG (1999). Rac downregulates Rho activity: reciprocal balance between both GTPases determines cellular morphology and migratory behavior. J Cell Biol 147:10091022.

Sander EE, van Delft S, ten Klooster JP, Reid T, van der Kammen RA, Michiels F, and Collard JG (1998). Matrixdependent Tiam1/Rac signaling in epithelial cells promotes either cell-cell adhesion or cell migration and is regulated by phosphatidylinositol 3-kinase. J Cell Biol 143:1385-1398.

Sastry SK and Horwitz AF (1996). Adhesion-growth factor interactions during differentiation: An integrated biological response. Dev Biol 180:455-467.

Slot JW and Geuze HJ (1985). A new method of preparing gold probes for multiple-labeling cytochemistry. Eur $\mathrm{J}$ Cell Biol 38:87-93.

Sormunen RT, Leong AS, Vaaraniemi JP, Fernando SS, and Eskelinen SM (1999). Immunolocalization of the fodrin, E-cadherin, and beta-catenin adhesion complex in infiltrating ductal carcinoma of the breast-comparison with an in vitro model. J Pathol 187:416-423.

Takaishi K, Sasaki T, Kotani H, Nishioka H, and Takai $Y$ (1997). Regulation of cell-cell adhesion by rac and rho small G proteins in MDCK cells. J Cell Biol 139:1047-1059.

Takeda H, Nagafuchi A, Yonemura S, Tsukita S, Behrens J, Birchmeier W, and Tsukita S (1995). V-src kinase shifts the cadherin-based cell adhesion from the strong to the weak state and beta catenin is not required for the shift. $\mathrm{J}$ Cell Biol 131:1839-1847.
Thomas SM and Brugge JS (1997). Cellular functions regulated by Src family kinases. Ann Rev Cell Dev Biol 13:513609.

Tsukita S, Oishi K, Akiyama T, Yamanashi Y, Yamamoto T, and Tsukita S (1991). Specific proto-oncogenic tyrosine kinases of src family are enriched in cell-to-cell adherens junctions where the level of tyrosine phosphorylation is elevated. J Cell Biol 113:867-879.

Vääräniemi J, Huotari V, Lehto VP, and Eskelinen S (1994). The effects of PMA and TFP and alterations in intracellular $\mathrm{pH}$ and calcium concentration on the membrane associations of phospholipid- binding proteins fodrin, protein kinase $\mathrm{C}$ and annexin II in cultured MDCK cells. Biochim Biophys Acta 1189:21-30.

Vääräniemi J, Palovuori R, Lehto VP, and Eskelinen S (1999). Translocation of MARCKS and reorganization of the cytoskeleton by PMA correlates with the ion selectivity, the confluence, and transformation state of kidney epithelial cell lines. J Cell Physiol 181:83-95.

Volberg T, Zick Y, Dror R, Sabanay I, Gilon C, Levitzki A, and Geiger B (1992). The effect of tyrosine-specific protein phosphorylation on the assembly of adherens-type junctions. EMBO J 11:1733-1742.

Wright JA and Huang A (1996). Growth factors in mechanisms of malignancy: roles for TGF-beta and FGF. Histol Histopathol 11:521-536.

Zondag GC, Evers EE, ten Klooster JP, Janssen L, van der Kammen RA, and Collard JG (2000). Oncogenic Ras downregulates Rac activity, which leads to increased Rho activity and epithelial-mesenchymal transition. J Cell Biol 149:775782. 